\title{
Imaging gravity waves in lower stratospheric AMSU-A radiances, Part 2: Validation case study
}

\author{
S. D. Eckermann ${ }^{1}$, D. L. Wu ${ }^{2}$, J. D. Doyle ${ }^{3}$, J. F. Burris $^{4}$, T. J. McGee $^{4}$, C. A. Hostetler ${ }^{5}$, L. Coy ${ }^{1}$, B. N. Lawrence ${ }^{6}$, \\ A. Stephens ${ }^{6}$, J. P. McCormack ${ }^{1}$, and T. F. Hogan ${ }^{3}$ \\ ${ }^{1}$ E. O. Hulburt Center for Space Research, Naval Research Laboratory, Washington, D.C., USA \\ ${ }^{2}$ Jet Propulsion Laboratory, California Institute of Technology, Pasadena, California, USA \\ ${ }^{3}$ Marine Meteorology Division, Naval Research Laboratory, Monterey, CA, USA \\ ${ }^{4}$ NASA Goddard Space Flight Center, Greenbelt, MD, USA \\ ${ }^{5}$ NASA Langley Research Center, Hampton, VA, USA \\ ${ }^{6}$ British Atmospheric Data Center, Rutherford Appleton Laboratory, Oxfordshire, UK
}

Received: 30 November 2005 - Published in Atmos. Chem. Phys. Discuss.: 27 March 2006

Revised: 3 August 2006 - Accepted: 5 August 2006 - Published: 14 August 2006

\begin{abstract}
Two-dimensional radiance maps from Channel 9 $(\sim 60-90 \mathrm{hPa})$ of the Advanced Microwave Sounding Unit (AMSU-A), acquired over southern Scandinavia on 14 January 2003, show plane-wave-like oscillations with a wavelength $\lambda_{h}$ of $\sim 400-500 \mathrm{~km}$ and peak brightness temperature amplitudes of up to $0.9 \mathrm{~K}$. The wave-like pattern is observed in AMSU-A radiances from 8 overpasses of this region by 4 different satellites, revealing a growth in the disturbance amplitude from 00:00 UTC to 12:00 UTC and a change in its horizontal structure between 12:00 UTC and 20:00 UTC. Forecast and hindcast runs for 14 January 2003 using highresolution global and regional numerical weather prediction (NWP) models generate a lower stratospheric mountain wave over southern Scandinavia with peak $90 \mathrm{hPa}$ temperature amplitudes of $\sim 5-7 \mathrm{~K}$ at 12:00 UTC and a similar horizontal wavelength, packet width, phase structure and time evolution to the disturbance observed in AMSU-A radiances. The wave's vertical wavelength is $\sim 12 \mathrm{~km}$. These NWP fields are validated against radiosonde wind and temperature profiles and airborne lidar profiles of temperature and aerosol backscatter ratios acquired from the NASA DC- 8 during the second SAGE III Ozone Loss and Validation Experiment (SOLVE II). Both the amplitude and phase of the stratospheric mountain wave in the various NWP fields agree well with localized perturbation features in these suborbital measurements. In particular, we show that this wave formed the type II polar stratospheric clouds measured by the DC-8 lidar. To compare directly with the AMSU-A data, we convert these validated NWP temperature fields into swath-scanned brightness temperatures using three-dimensional Channel 9 weighting functions and the actual AMSU-A scan patterns from each of the 8 overpasses of this region. These NWP-
\end{abstract}

Correspondence to: S. D. Eckermann

(stephen.eckermann@nrl.navy.mil) based brightness temperatures contain two-dimensional oscillations due to this resolved stratospheric mountain wave that have an amplitude, wavelength, horizontal structure and time evolution that closely match those observed in the AMSU-A data. These comparisons not only verify gravity wave detection and horizontal imaging capabilities for AMSU-A Channel 9, but provide an absolute validation of the anticipated radiance signals for a given three-dimensional gravity wave, based on the modeling of Eckermann and $\mathrm{Wu}$ (2006).

\section{Introduction}

The Advanced Microwave Sounding Unit (AMSU) is a cross-track-scanning passive microwave sounding instrument currently deployed on the NOAA-15 though NOAA18 meteorological weather satellites (Kidder et al., 2000) and NASA's Earth Observation System (EOS) Aqua satellite (Lambrigtsen, 2003). Radiances from the AMSU-A temperature channels are important inputs to operational numerical weather prediction (NWP) systems: they improve specifications of global atmospheric initial conditions, which lead to significant increases in forecasting skill (e.g., Baker et al., 2005). Radiances from AMSU-A have better spatial resolution than those from previous operational cross-track microwave scanners, due to a narrower antenna beam that yields smaller horizontal measurement footprints, and more measurement channels with improved radiometric accuracy. In fact, AMSU-A produces too much fine-scale global data for operational weather centers to cope with at present, and so various "superobbing" algorithms must be applied to thin these data prior to operationally assimilating them (Baker et al., 2005).

Published by Copernicus GmbH on behalf of the European Geosciences Union. 
This improved resolution and accuracy should allow AMSU-A to resolve finer-scale atmospheric features than earlier instruments. One focus of investigation has been stratospheric gravity waves, which are poorly resolved by most satellite remote-sensing instruments. Wu (2004) was the first to investigate this possibility experimentally by isolating along-track fluctuations in radiances acquired from AMSU-A stratospheric channels at various cross-track scan angles. Global maps of these variances in the extratropical Southern Hemisphere showed enhancements over mountains and at the edge of the polar vortex that resembled similarly enhanced radiance variances from the Microwave Limb Sounder (MLS) on the Upper Atmosphere Research Satellite (UARS). Since the MLS radiance variance is known to originate from resolved gravity wave oscillations (e.g., McLandress et al., 2000; Jiang et al., 2004), these correlations appear to show AMSU-A resolving stratospheric gravity waves.

Whereas MLS cyclically stares at or scans the limb, AMSU-A cyclically scans the atmosphere beneath the satellite at 30 equispaced off-nadir cross-track viewing angles between $\pm 48.33^{\circ}$. As the satellite orbits, this scanning pattern sweeps out two-dimensional "pushbroom" images of atmospheric radiances beneath the satellite, rather than the onedimensional horizontal cross sections from MLS. Wu and Zhang (2004) isolated small-scale structure in AMSU-A radiances at all 30 scan angles and plotted these perturbations at the measurement locations to yield a swath-scanned horizontal image of the perturbation field. Focusing on a region off the northeastern coast of the USA on 19-21 January 2003, they found plane-wave-like oscillations that appeared to capture the horizontal structure of stratospheric gravity waves radiated from the jet stream.

While correlations between AMSU-A radiance perturbations and wave fluctuations observed in MLS radiances ( $\mathrm{Wu}$, 2004) or simulated by a mesoscale model (Wu and Zhang, 2004) certainly suggest that AMSU-A can resolve gravity waves, they do not provide quantitative insights into why and how wave signals manifest in these data. To provide some theoretical insight, Eckermann and Wu (2006) developed a simplified model of the in-orbit acquisition of radiances by AMSU-A Channel 9 on both the NOAA and EOS Aqua satellites. The three-dimensional temperature weighting functions that this modeling generated were in turn used to specify how gravity waves with different temperature amplitudes, horizontal propagation directions, and vertical and horizontal wavelengths manifested as oscillatory signals in swath-scanned Channel 9 radiance imagery. These simulations indicated that a lower stratospheric gravity wave which had a temperature amplitude of $\gtrsim 3 \mathrm{~K}$, a vertical wavelength of $\gtrsim 10 \mathrm{~km}$, and a horizontal wavelength of $\gtrsim 150-200 \mathrm{~km}$ should appear as a detectable oscillation in Channel 9 brightness temperatures (i.e., above the nominal $\pm 0.2 \mathrm{~K}$ noise floor). If any of these threshold criteria is not met, the gravity wave is probably not visible to AMSU-A Channel 9. The simulations also showed how these resolved radiance signals, when mapped horizontally, provided a two-dimensional image of the wave's horizontal structure, with some cross-track distortions introduced due to the limb effect and variations in footprint diameters versus scan angle.

These predicted amplitude and wavelength thresholds for gravity wave detection by AMSU-A Channel 9 provide the same basic guidance as previous modeling studies for other satellite instruments (e.g., McLandress et al., 2000; Preusse et al., 2002; Jiang et al., 2004). They are important in specifying the kinds of waves being measured and what information these data can and cannot provide (see, e.g., Alexander, 1998; Wu et al., 2006). However, this AMSU-A forward model provides important additional guidance.

First, it models how two-dimensional gravity wave structure is both imaged horizontally and distorted in swathscanned AMSU-A radiances. Horizontal gravity wave imaging is an important new satellite measurement capability, heretofore only hinted at by a few limited observational case studies (Dewan et al., 1998; Wu and Zhang, 2004) and never previously modeled. Second, if the three-dimensional wavelength and amplitude structure of the gravity wave is known, the forward model of Eckermann and Wu (2006) makes specific predictions about the absolute brightness temperature amplitudes that should be seen by Channel 9 . Indeed, given a complete gridded three-dimensional temperature field, the forward model can convert these temperatures into brightness temperature maps that can be compared directly with the AMSU-A data. Previous models of the visibility characteristics of specific satellite instruments have only been used to crudely filter model-generated wave fields, so that the relative variations in observed and modeled wave variances can be more meaningfully compared, such as geographical and seasonal variability (McLandress et al., 2000; Jiang et al., $2002,2004)$. No study to date has converted model-predicted gravity wave fields into absolute radiance oscillations whose amplitudes and phases can be compared directly with the observed radiance oscillations.

Here we attempt an absolute observational validation of the forward modeling predictions of Eckermann and $\mathrm{Wu}$ (2006) of gravity wave signals in AMSU-A Channel 9 radiances. We focus on wavelike structures imaged in swathscanned Channel 9 radiances over southern Scandinavia on 14 January 2003. To provide estimates of three-dimensional gravity wave temperature perturbations in this region of the lower stratosphere on this day, we analyze high-resolution forecast and hindcast fields from NWP models, validating them against available suborbital observations in this region, such as DC-8 lidar data acquired during the SAGE III Ozone Loss and Validation Experiment (SOLVE II). We then apply the forward model of Eckermann and Wu (2006) to convert these validated NWP temperature fields into swath-scanned Channel 9 brightness temperature maps, using the actual AMSU-A scanning patterns during each of the 8 satellite overpasses that occurred at different times on this day. These 
NWP-based radiance perturbations are compared to those measured by AMSU-A, to assess how closely the observed horizontal structure, wavelengths, amplitudes and time evolution of the measured fluctuations are reproduced.

\section{Data sources}

\subsection{Advanced Microwave Sounding Unit-A}

Since the companion paper of Eckermann and Wu (2006) provides a description of AMSU and develops a model of its Channel 9 stratospheric radiance acquisition, here we provide only a brief summary of the salient features of this instrument for this observational study.

AMSU-A has 15 measurement channels, 6 of which (Channels 9-14) are stratospheric temperature channels. Channels 9 though 14 sample wing line thermal oxygen emissions centered at $57.290 \mathrm{GHz}$. The one-dimensional (1D) vertical weighting functions at nadir for these channels peak progressively higher in the stratosphere, from $\sim 90 \mathrm{hPa}$ for Channel 9 though to $\sim 2.5 \mathrm{hPa}$ for Channel 14 (Kidder et al., 2000). We analyze only Channel 9 radiances in this study.

The AMSU-A cross-track scanning pattern consists of $j=1 \ldots 30$ sequential step-and-stare measurements at equispaced off-nadir beam angles $\beta_{j}$ between $\pm 48.33^{\circ}$, distributed symmetrically about the subsatellite point: see Fig. 1 of Eckermann and $\mathrm{Wu}$ (2006). The cross-track swath width at stratospheric altitudes is $\sim 2100 \mathrm{~km}$ for the NOAA satellites. Each scan cycle takes $8 \mathrm{~s}$ to complete, so that data from successive scans are separated by $\sim 60 \mathrm{~km}$ along track given a $7.4 \mathrm{~km} \mathrm{~s}^{-1}$ satellite velocity. At the near-nadir beam positions $j=15,16$, the half-power horizontal measurement footprints are nearly circular with diameters of $\sim 48 \mathrm{~km}$ for Channel 9 on the NOAA satellites. These footprints become broader and more elliptically elongated cross-track at the offnadir measurement angles (Kidder et al., 2000; Eckermann and $\mathrm{Wu}, 2006)$. Swath widths and footprint diameters are somewhat smaller for the AMSU-A on EOS Aqua due to its lower orbit altitude of $705 \mathrm{~km}$ compared to $833 \mathrm{~km}$ for the NOAA satellites (see Fig. 6 of Eckermann and Wu, 2006). The altitude of peak Channel 9 sensitivity increases with increasing $\left|\beta_{j}\right|$ due to the limb effect (Goldberg et al., 2001; Eckermann and $\mathrm{Wu}, 2006$ ), to a maximum peak altitude of $\sim 65 \mathrm{hPa}$ at the outermost scan angles (Fig. 1b; see also Fig. 4 of Eckermann and $\mathrm{Wu}, 2006$ ). Here we analyze raw radiances to which no limb adjustment procedures (Goldberg et al., 2001) have been applied.

\subsection{NASA DC-8 lidar data}

The Langley Research Center (LaRC) aerosol lidar operates in comanifested form with the Goddard Space Flight Center (GSFC) Airborne Raman Ozone, Temperature and Aerosol Lidar (AROTAL) on NASA's DC-8 research aircraft. The

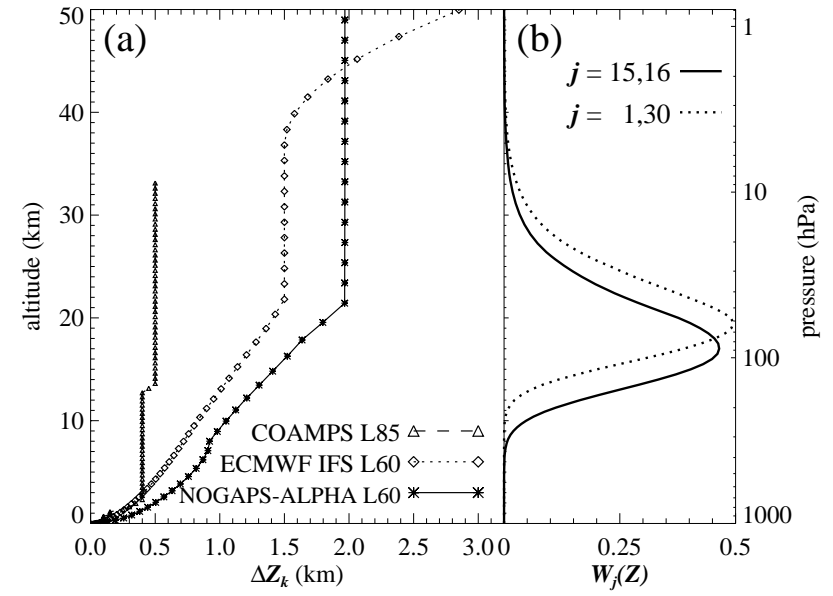

Fig. 1. (a) Vertical layer thicknesses $\Delta Z_{k}$ of various NWP model levels. COAMPS altitudes and thicknesses are geometric heights for a surface altitude of $0 \mathrm{~km}$, whereas NOGAPS-ALPHA and ECMWF IFS altitudes and thicknesses are pressure heights assuming a scale height of $7 \mathrm{~km}$ and a nominal sea-level surface pressure of $1013.25 \mathrm{hPa}$. (b) AMSU-A Channel 91 -D vertical weighting functions $W_{j}(Z)$ for the near-nadir beams $(j=15,16)$ and far offnadir beams $(j=1,30)$ from Eckermann and $\mathrm{Wu}(2006)$.

lidars transmit vertically and collect backscattered radiation with a zenith-viewing telescope.

The GSFC/LaRC lidar emits laser pulses at 1064, 532, and $355 \mathrm{~nm}$, the fundamental, doubled, and tripled frequencies, respectively, from a neodymium:yttrium/aluminum/garnet (Nd:YAG) laser. Here we study aerosol backscatter ratios (ABRs) derived from GSFC/LaRC lidar backscatter at $1064 \mathrm{~nm}$,

$S_{1064}=\frac{\beta_{\text {aerosol }}+\beta_{\text {air }}}{\beta_{\text {air }}}$,

where $\beta_{\text {aerosol }}$ and $\beta_{\text {air }}$ are the backscatter coefficients from aerosol and air molecules, respectively. The lidar measures the total backscatter $\beta_{\text {aerosol }}+\beta_{\text {air }}$ : $\beta_{\text {air }}$ is derived using atmospheric densities from meteorological analyses along track. GSFC/LaRC lidar ABRs are issued at $75 \mathrm{~m}$ vertical resolution every $\sim 15 \mathrm{~s}$.

Stratospheric ABRs provide first-order discrimination among different types of polar stratospheric clouds (PSCs). PSC-free regions yield $S_{1064} \sim 1$. Type I PSCs, composed of nitric acid trihydrate (NAT, type Ia) or supercooled ternary solutions (STS, type Ib) yield $S_{1064} \sim 3-30$, whereas type II PSCs (ice) yield $S_{1064} \sim 50-500$ (e.g., Fueglistaler et al., 2003).

We also utilize Rayleigh temperature profiles derived from $355 \mathrm{~nm}$ (YAG) AROTAL returns. These temperatures were retrieved without the $387 \mathrm{~nm}$ Raman channel data used in some previous AROTAL measurements (Burris et al., 2002a), and so are prone to errors in the presence of PSCs and sunlight (Burris et al., 2002b). Profiles are issued every 
21-22 $\mathrm{s}$ at a vertical resolution of $150 \mathrm{~m}$ from just above the aircraft to $\sim 60 \mathrm{~km}$ altitude, though the intrinsic temporal and vertical data resolutions are somewhat coarser (Burris et al., 2002a).

\section{Models}

\subsection{Numerical weather prediction models}

To validate specific gravity waves resolved in AMSU-A radiances, we would ideally compare directly with suborbital measurements of the wave field. However, to model gravity wave-induced fluctuations in the AMSU-A radiances adequately, we need to know the full three-dimensional (3-D) structure of the wave field (Eckermann and $\mathrm{Wu}, 2006$ ). Suborbital gravity wave data are much too sparse to characterize gravity waves three-dimensionally, yet without this information these two data sets cannot be meaningfully compared and cross-validated.

Thus, to provide the necessary 3-D wave fields that can link the AMSU-A and suborbital measurements, we analyze output from three different numerical weather prediction (NWP) models, each of which bring some unique capabilities to our validation study. All of these models were run at high spatial resolution in order to explicitly resolve any long wavelength gravity wave activity that AMSU-A might be sensitive to.

\subsubsection{ECMWF IFS}

We use forecast and analysis fields issued operationally by the European Centre for Medium-Range Weather Forecasts (ECMWF) Integrated Forecast System's (IFS) $\mathrm{T}_{\mathrm{L}}$ 511L60 global spectral model (Ritchie et al., 1995; Untch and Hortal, 2004). We use global gridpoint fields on all 60 hybrid $\sigma-p$ vertical model levels from the surface to $0.1 \mathrm{hPa}$ issued on the reduced N256 linear Gaussian grid that progressively thins the number of points around a latitude circle, from 1024 at the equator to 192 at $\pm 80^{\circ}$ latitude. Forecasts and analyses are available every $6 \mathrm{~h}$, starting at 00:00 UTC.

\subsubsection{NOGAPS-ALPHA}

Since the six hourly output from the ECMWF IFS proves too sparse for precise comparisons with AMSU-A data, we performed hindcasts using high resolution Navy NWP models.

Global NWP for the U.S. Department of Defense (DoD) is provided by the Naval Research Laboratory's (NRL) Navy Operational Global Atmospheric Prediction System (NOGAPS), which is run operationally at the Fleet $\mathrm{Nu}-$ merical Meteorology and Oceanography Center (FNMOC) (Hogan and Rosmond, 1991). Here we use a developmental version of the NOGAPS global spectral forecast model with Advanced Level Physics and High Altitude (NOGAPS-
ALPHA: Eckermann et al., 2004; McCormack et al., 2004; Allen et al., 2006).

The NOGAPS-ALPHA hindcasts performed here used a "cold start" procedure in which global analyzed winds and geopotential heights on reference pressure levels and a $1^{\circ} \times 1^{\circ}$ grid are read in and interpolated to the model's quadratic Gaussian grid and hybrid $\sigma-p$ levels. Initial model temperatures are computed hydrostatically from the geopotentials. The model was then forwarded in time without meteorological assimilation update cycles. To initialize our runs for January 2003 at altitudes below $10 \mathrm{hPa}$, two different Navy analyses were available: (a) archived operational analysis from the then-operational Navy multivariate optimum interpolation (MVOI) system (Barker, 1992); (b) reanalysis fields for this period from the NRL Atmospheric Variational Data Assimilation System (NAVDAS) (Daley and Barker, 2001), which assimilated AMSU-A radiances from the NOAA 15 and 16 satellites. NAVDAS with AMSU-A radiance assimilation became operational at FNMOC on 9 June 2004 and has significantly improved NOGAPS forecast skill (Baker et al., 2005; Allen et al., 2006). While NOGAPSALPHA runs using both analyses were performed and analyzed for cross-validation purposes, here we will only show results from runs initialized with the NAVDAS reanalysis.

From $10-0.4 \mathrm{hPa}$ we initialized using FNMOC's operational "STRATOI" analysis (see Sect. 4 of Goerrs and Phoebus, 1992), whose primary data source is ATOVS temperature retrievals issued by NOAA's National Environmental Satellite, Data and Information Service (NESDIS) (Reale et al., 2004). From $0.4-0.005 \mathrm{hPa}$ we have no Navy analysis fields available for January 2003 (STRATOI was extended to $0.1 \mathrm{hPa}$ in June 2003). Thus we extrapolated the $0.4 \mathrm{hPa}$ STRATOI fields upwards by progressively relaxing them with increasing altitude to zonal-mean climatological winds from the UARS Reference Atmosphere Project (URAP; Swinbank and Ortland, 2003) and temperatures from the 1986 COSPAR International Reference Atmosphere (CIRA; Fleming et al., 1990): for algorithm details, see Eckermann et al. (2004). This final global initial state is adjusted within NOGAPS-ALPHA for hydrostatic balance then run through a nonlinear normal mode filter (Errico et al., 1988), to suppress potential for any spurious gravity wave generation due to unbalanced initial conditions. Surface ice concentrations, land/sea surface temperatures and snow depths are also initialized using FNMOC analysis and are updated from archived analysis every $12 \mathrm{~h}$ in our model runs.

We used a T239L60 model configuration extending from the ground up to $0.005 \mathrm{hPa}$ on hybrid $\sigma-p$ levels with a first purely isobaric half level at $87.5 \mathrm{hPa}$. Model layer thicknesses are shown in Fig. 1a. The "standard" Rayleigh friction profile of Butchart and Austin (1998) was applied to the upper model levels as a crude representation of mesospheric gravity wave drag. This, along with enhanced spectral diffusion and Newtonian cooling in the top two model layers, effectively suppressed downward reflection of resolved gravity 
waves from the model top. We saved model fields spectrally every hour. Gridpoint fields were obtained by retransforming onto the $720 \times 360$ quadratic Gaussian grid $\left(\sim 0.5^{\circ}\right.$ resolution) at all 60 model $\sigma-p$ levels.

\subsubsection{COAMPS}

NRL's Coupled Ocean/Atmosphere Mesoscale Prediction System (COAMPS ${ }^{\circledR}$ ) is FNMOC's regional operational NWP system (Hodur, 1997). COAMPS hindcast runs here used two nested $169 \times 169$ horizontal grids of $30 \mathrm{~km}$ and $10 \mathrm{~km}$ horizontal grid spacing, and 85 nonuniformly-spaced terrain-following vertical levels (Gal-Chen and Somerville, 1975) extending to a top geometric altitude of $33 \mathrm{~km}$ (see Fig. 1a). The top several kilometers contained a numerical sponge layer to absorb upward-propagating gravity waves at the upper boundary. As for the NOGAPS-ALPHA runs, we performed separate COAMPS runs initialized in a cold-start procedure using archived MVOI analyses and NAVDAS reanalyses, with output from the latter runs only analyzed in this study. Archived NOGAPS forecast fields were used to specify the lateral boundary conditions every $6 \mathrm{~h}$. Output fields were saved every hour on the intrinsic model grid.

The primary purpose of the COAMPS runs is to provide higher resolution fields than the global models in order to resolve gravity wave fields better. Thus, subsequent analysis will focus only on the high horizontal resolution $10 \times 10 \mathrm{~km}^{2}$ fields from the nested COAMPS run.

\subsection{AMSU-A radiance acquisition model}

To relate gravity waves in the three-dimensional gridded NWP temperature fields $T$ with those observed in Channel 9 AMSU-A brightness temperatures $T_{B}$, we convert temperatures into a model brightness temperature field

$$
\begin{aligned}
& T_{B_{\mathrm{NWP}}}\left(X_{j}, Y_{j}\right)=\iiint W_{j}\left(X-X_{j}, Y-Y_{j}, Z\right) \\
& T(X, Y, Z) d X d Y d Z,
\end{aligned}
$$

using the three-dimensional AMSU-A weighting functions $W_{j}(X, Y, Z)$ from the modeling study of Eckermann and $\mathrm{Wu}$ (2006). Following their notation (see their Fig. 1), $X$ and $Y$ are along-track and cross-track distances, respectively, $Z$ is pressure altitude, $j$ is beam position (as defined by its crosstrack scan angle $\beta_{j}$ : see Sect. 2.1), and $\left(X_{j}, Y_{j}\right)$ is the location of the peak $W_{j}(X, Y, Z)$ response which we take to be the measurement location. Equation (2) is integrated over the full range of permissable $X, Y$ and $Z$ values.

To evaluate Eq. (2) numerically, we must regrid the NWP temperatures from their longitude, latitude and terrainfollowing vertical levels onto the same regular Cartesian $(X, Y, Z)$ grid used for $W_{j}(X, Y, Z)$. The next 4 paragraphs explain how we do this.

First, we vertically interpolate the NWP temperature fields onto a regular pressure height grid of $\Delta Z=0.5 \mathrm{~km}$, a choice based on the minimum intrinsic vertical model resolutions in Fig. 1a. Weighting functions $W_{j}(X, Y, Z)$ are interpolated onto this same vertical grid.

For a given scan cycle, each of the $j=1 \ldots 30$ AMSU-A radiance measurements comes registered at its ground-level footprint longitude $\hat{\lambda}_{j}$ and latitude $\hat{\phi}_{j}$. Using spherical geometry (see Fig. 16 of Eckermann and Wu, 2006), we correct these locations by moving along the line-of-sight ray from the surface to the $\sim 60-90 \mathrm{hPa}$ altitude where the relevant weighting function $W_{j}(X, Y, Z)$ peaks. The NWP fields are distributed at gridpoints $\left(\hat{\lambda}_{i}, \hat{\phi}_{i}\right)$. For each AMSU-A measurement at beam position $j$, we compute great circle distances $d_{i, j}$ from these gridpoints $\left(\hat{\lambda}_{i}, \hat{\phi}_{i}\right)$ to this beam's (corrected) footprint location $\left(\hat{\lambda}_{j}, \hat{\phi}_{j}\right)$. We retain model temperatures $T\left(\hat{\lambda}_{i}, \hat{\phi}_{i}, Z\right)$ only at those gridpoints $i$ for which $d_{i, j} \leq 300 \mathrm{~km}$. Since AMSU-A footprint radii are $<100 \mathrm{~km}$ at every beam position (Eckermann and $\mathrm{Wu}, 2006$ ), gridpoint fields more than $300 \mathrm{~km}$ from the peak of the weighting function can be safely discarded as lying well outside this beam's field of view. This process significantly thins the NWP field and speeds up the subsequent numerical computation of Eq. (2).

Next the scan axes $(X, Y)$ must be specified on the sphere. The Y-axis vector direction is computed as the bearing angle $\gamma_{j, s s}$ from true north from the subsatellite point for this scan, $\left(\hat{\lambda}_{s s}, \hat{\phi}_{s s}\right)$, to the current footprint location $\left(\hat{\lambda}_{j}, \hat{\phi}_{j}\right) . Y_{j}$ is the great circle distance $d_{j, s s}$ between $\left(\hat{\lambda}_{j}, \hat{\phi}_{j}\right)$ and $\left(\hat{\lambda}_{s s}, \hat{\phi}_{s s}\right)$, and $X_{j}=0$ (since AMSU-A does not scan along-track). For the negative scan angles $\beta_{j}$, we set $Y_{j}=-d_{j, s s}$.

To regrid the retained NWP temperatures $T\left(\hat{\lambda}_{i}, \hat{\phi}_{i}, Z\right)$ onto the $(X, Y)$ grid, we compute great circle distances $d_{i, s s}$ between all the retained gridpoints $i$ and the subsatellite point, as well as their bearing angles $\gamma_{i, s s}$ from the subsatellite point. We use these $d_{i, s s}$ and $\gamma_{i, s s}$ values to compute corresponding coordinates $\left(X_{i}, Y_{i}\right)$ using Napier's Rules for spherical right-angled triangles. After triangulating all the $\left(X_{i}, Y_{i}\right)$ data, we linearly interpolate the temperatures at each level onto a regular $(X, Y)$ grid of length $380 \mathrm{~km}$ and resolution $5 \mathrm{~km}$ in both directions centered at $\left(X_{j}, Y_{j}\right)$.

With $T(X, Y, Z)$ and $W_{j}(X, Y, Z)$ now on a common $(X, Y, Z)$ grid, we evaluate Eq. (2) numerically using rectangular integration over this entire gridded $(X, Y, Z)$ domain.

\section{Radiances and temperatures over Scandinavia on 14 January 2003}

Figure 2 plots AMSU-A Channel 9 brightness temperatures $T_{B}\left(\hat{\lambda}_{j}, \hat{\phi}_{j}\right)$ acquired during the ascending and descending overpasses of Scandinavia by EOS Aqua, NOAA-15, NOAA-16 and NOAA-17 on 14 January 2003. The maps are arranged in chronological order, with data plotted as colorcoded elliptical footprint pixels with dimensions specified by 
(a) EOS Aqua 0116 UTC

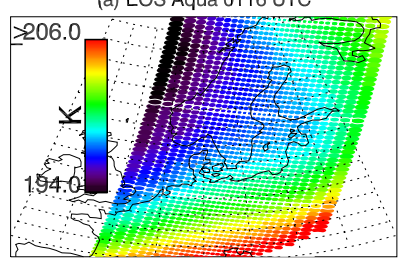

(c) NOAA-15 0650 UTC

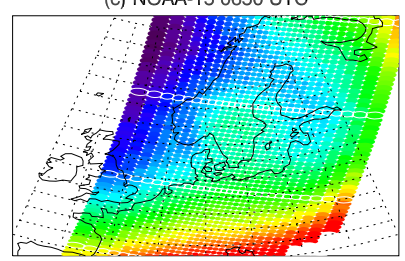

(e) NOAA-16 1221 UTC

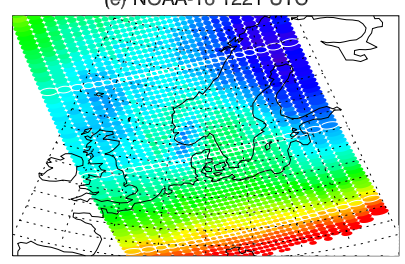

(g) NOAA-15 1641 UTC

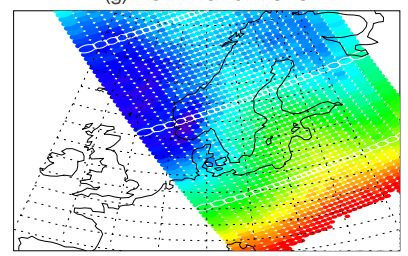

(b) NOAA-16 0226 UTC

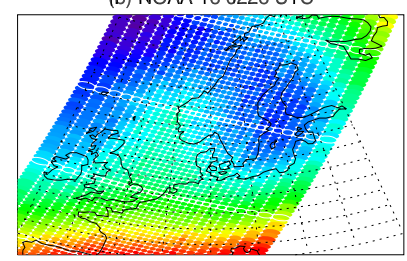

(d) NOAA-17 1033 UTC

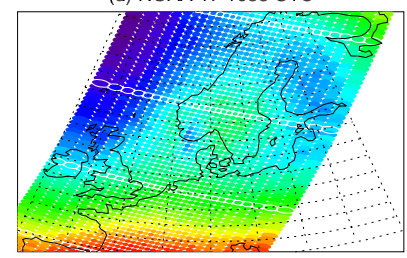

(f) EOS Aqua 1229 UTC

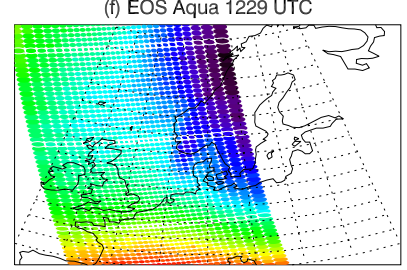

(h) NOAA-17 2023 UTC

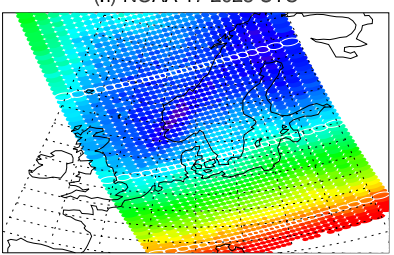

Fig. 2. AMSU-A Channel 9 brightness temperatures $T_{B}\left(\hat{\lambda}_{j}, \hat{\phi}_{j}\right)$ measured during the ascending and descending overpasses of Scandinavia by EOS Aqua, NOAA-15, NOAA-16, and NOAA-17. These values (in Kelvin) are plotted as color-coded footprint ellipses at the measurement location: see color bar in panel (a). White curves outline these measurement footprints for every tenth scan. Panels are arranged in chronological order, with the universal time and satellite platform of the overpass given in the plot title.

the Channel 9 radiance acquisition model of Eckermann and Wu (2006): see their Fig. 6.

Figure 3 plots the 6-hourly ECMWF IFS analysis temperatures for 14 January 2003 at $85 \mathrm{hPa}$ and $65 \mathrm{hPa}$, the approximate vertical range of the peak AMSU-A weighting function responses at various beam positions (see Fig. 1b). Like the brightness temperatures, the analysis temperatures transition from warmer mid-latitude values to much colder values in and around Scandinavia. McCormack et al. (2004) showed that the very cold stratospheric temperatures over Scandinavia on 14 January 2003 were driven by adiabatic uplift from an anticyclonic upper-tropospheric ridge over Western Europe and a weak wave- 1 stratospheric disturbance that pushed the vortex core off the pole towards Scandinavia. These vortex disturbances presaged a minor stratospheric warming, which split the vortex about a week later (McCor-

mack et al., 2004) and shut off much of the early season PSC formation and ozone loss chemistry (Feng et al., 2005).

Despite gross similarites, variations in the brightness temperature maps from measurement to measurement in Fig. 2 do not correlate obviously with the analysis temperatures in Fig. 3. Since adjacent AMSU-A measurements can be separated by an hour or less, the 6-hourly resolution of the ECMWF analysis temperatures is too coarse to investigate these variations systematically, and so we turn now to hourly temperature fields from the NOGAPS-ALPHA runs.

Figure 4 plots hindcast NOGAPS-ALPHA temperatures at times and altitudes corresponding to those plotted in Fig. 3. The geographical structure and temporal evolution are very similar to the ECMWF analysis fields. In the "cold pool" regions, NOGAPS-ALPHA shows a cold bias of $\sim 1-2 \mathrm{~K}$ relative to the ECMWF analysis, which originates mostly from the NAVDAS fields used for initialization (not shown), which have a $1-2 \mathrm{~K}$ cold bias relative to the ECMWF analysis in these cold-pool regions. Apart from this the comparison is very good, even down to details in the small-scale temperature oscillations over southern Scandinavia and Scotland, which we will focus on subsequently.

Next, we compute synthetic brightness temperature fields $T_{B_{\mathrm{NWP}}}\left(\hat{\lambda}_{j}, \hat{\phi}_{j}\right)$ from these NOGAPS-ALPHA temperatures by evaluating Eq. (2) via the methods outlined in Sect. 3.2. For each AMSU-A measurement in Fig. 2, we evaluate Eq. (2) using the hourly NOGAPS-ALPHA temperature field closest in time to this satellite overpass. Results are plotted in Fig. 5.

Synthetic NOGAPS-ALPHA brightness temperatures in each panel of Fig. 5 compare very well in both magnitude and horizontal structure with the corresponding AMSU-A data in Fig. 2. This indicates that most of the panel-to-panel differences in Fig. 2 do not originate from biases among the various instruments deployed on different satellite platforms. Rather, most of the variability comes from the limb effect, which causes the far off-nadir measurements at the edges of the cross-track swaths to peak at $\sim 65 \mathrm{hPa}$, while those nearnadir measurements in the middle of the swath peak nearer $85 \mathrm{hPa}$ (Goldberg et al., 2001; Eckermann and Wu, 2006).

Thus, for example, the very cold brightness temperatures at 01:16 UTC to the west of Scandinavia in Figs. 2a and 5a can be understood in terms of far off-nadir measurements at the edge of the swath that measure the compact core of cold $65 \mathrm{hPa}$ temperatures in Fig. $4 \mathrm{~b}$. The overpass $1 \mathrm{~h}$ later in Figs. $2 \mathrm{~b}$ and $5 \mathrm{~b}$ measured warmer brightness temperatures here since it sampled this region with near-nadir beams which measured the significantly warmer $85 \mathrm{hPa}$ temperatures in Fig. $4 \mathrm{a}$, while the off-nadir beams sampled the warmer $65 \mathrm{hPa}$ temperatures located either side of this cold core in Fig. 4b.

The excellent reproduction of the measured brightness temperatures of Fig. 2 by this synthetic field in Fig. 5 governed by NWP model output gives us confidence that both our 3-D NWP hindcast temperature fields and the 3-D model 


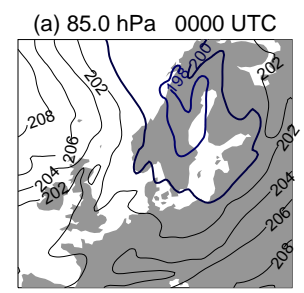

(b) $65.0 \mathrm{hPa} 0000$ UTC

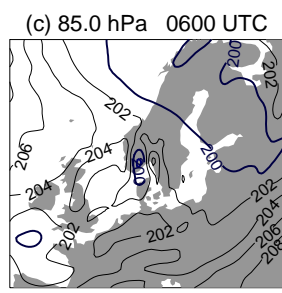

(d) $65.0 \mathrm{hPa} 0600$ UTC

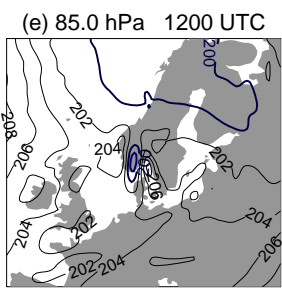

(f) $65.0 \mathrm{hPa} 1200 \mathrm{UTC}$

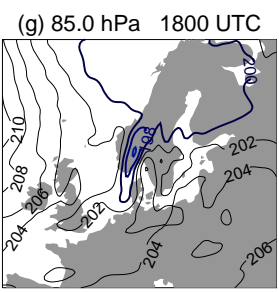

(h) $65.0 \mathrm{hPa} 1800$ UTC
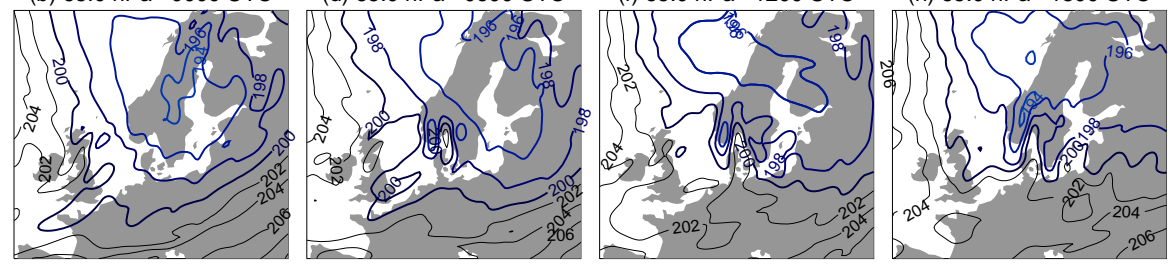

Fig. 3. ECMWF IFS $\mathrm{T}_{\mathrm{L}}$ 511L60 6-hourly analysis temperatures for 14 January 2003 at $85 \mathrm{hPa}$ (top row) and $65 \mathrm{hPa}$ (bottom row), corresponding roughly to the peak altitudes of the near-nadir and far off-nadir Channel 9 weighting functions, respectively. Contour interval is $2 \mathrm{~K}$ and temperatures below $200 \mathrm{~K}$ have blue contour shading.

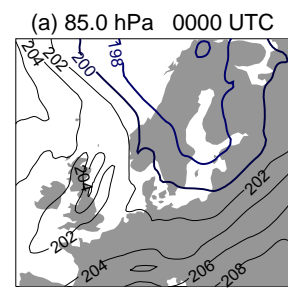

(b) $65.0 \mathrm{hPa} 0000 \mathrm{UTC}$

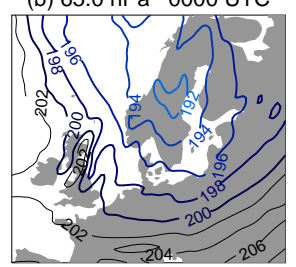

(c) $85.0 \mathrm{hPa} 0600$ UTC

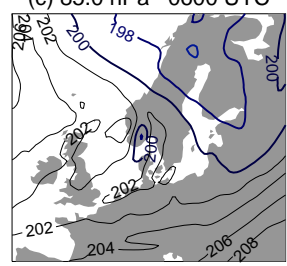

(d) $65.0 \mathrm{hPa} 0600 \mathrm{UTC}$

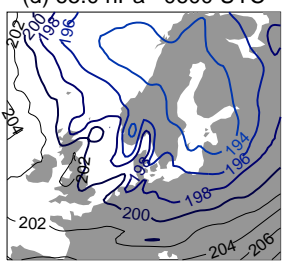

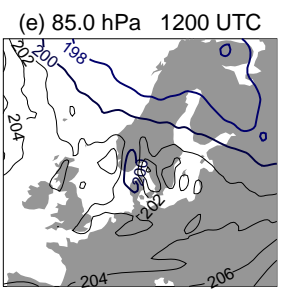

(f) $65.0 \mathrm{hPa} 1200 \mathrm{UTC}$

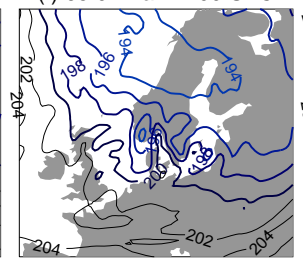

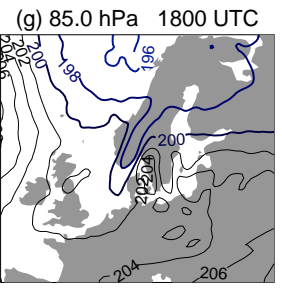

(h) $65.0 \mathrm{hPa} 1800 \mathrm{UTC}$

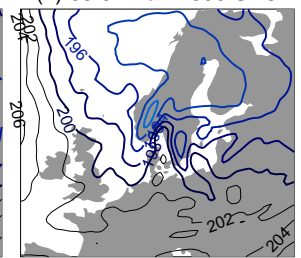

Fig. 4. As in Fig. 3 but plotting hindcast fields from the NOGAPS-ALPHA T239L60 hindcast temperatures initialized with NAVDAS reanalyses on 13 January 2003 at 12:00 UTC (i.e. 12-30 h forecast fields).

weighting functions of Eckermann and $\mathrm{Wu}(2006)$ are sufficiently accurate to permit quantitative intercomparisons between the AMSU-A radiances and NWP temperature fields.

\section{Gravity waves over Scandinavia on 14 January 2003}

\subsection{AMSU-A measurements}

To isolate perturbations $T_{B}^{\prime}\left(\hat{\lambda}_{j}, \hat{\phi}_{j}\right)$ from the raw brightness temperatures in Fig. 2, we estimated a large horizontal-scale background field $\bar{T}_{B}\left(\hat{\lambda}_{j}, \hat{\phi}_{j}\right)$ using the following algorithm.

First, we performed 11-point $(\sim 650 \mathrm{~km})$ along-track smoothing of the radiances. These smoothed data were then fitted cross track for each scan using a least-squares sixthorder polynomial. These curves fitted both systematic crosstrack trends in the radiances due to the limb effect and any instrumental biases (e.g., Wu, 2004; Eckermann and $\mathrm{Wu}$, 2006), as well as geophysical gradients produced by horizontal structure in the temperature fields evident in Figs. 25. Fitted data were then subjected to 5-point along-track smoothing to yield our final $\bar{T}_{B}\left(\hat{\lambda}_{j}, \hat{\phi}_{j}\right)$ field. The widths of these along-track averaging windows and the order of the polynominal fits were all tuned to give the best tradeoff between retaining as much long wavelength gravity wave structure in the data as possible (aligned at any direction with respect to the scan axis), while removing the background radiance structure evident in Fig. 2 as completely as possible.

Perturbations were isolated by differencing at each measurement location, i.e.,

$T_{B}^{\prime}\left(\hat{\lambda}_{j}, \hat{\phi}_{j}\right)=T_{B}\left(\hat{\lambda}_{j}, \hat{\phi}_{j}\right)-\bar{T}_{B}\left(\hat{\lambda}_{j}, \hat{\phi}_{j}\right)$.

We applied $3 \times 3$ point smoothing to these perturbation 

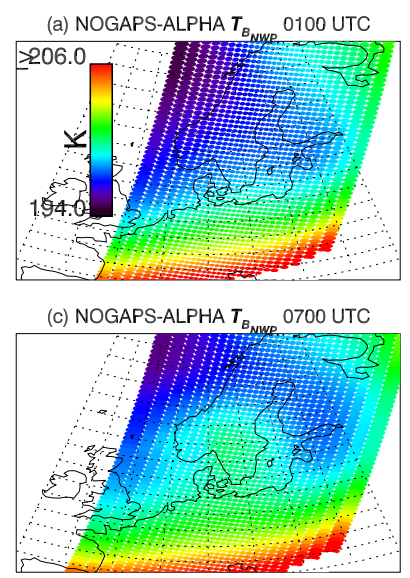

(e) NOGAPS-ALPHA $T_{B} \quad 1200$ UTC

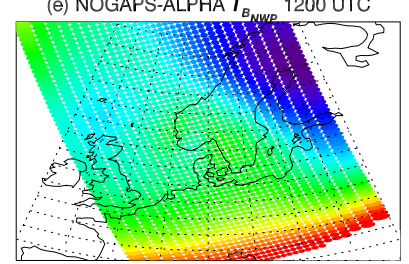

(g) NOGAPS-ALPHA $T_{B_{\text {NUP }}} 1700$ UTC

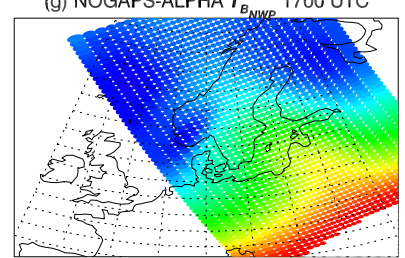

(b) NOGAPS-ALPHA $T_{B_{\text {NWP }}} 0200$ UTC

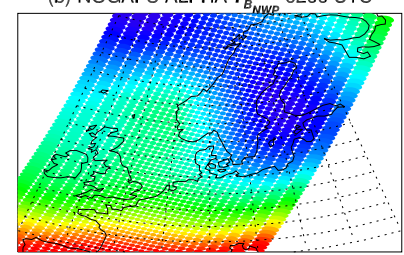

(d) NOGAPS-ALPHA $T_{B_{\text {MUP }}} 1000$ UTC

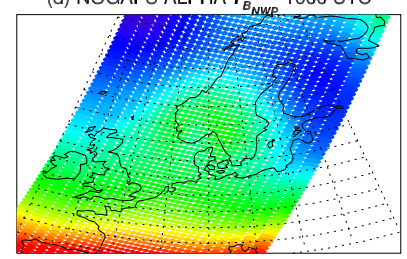

(f) NOGAPS-ALPHA $T_{B_{\text {NuP }}} 1200$ UTC

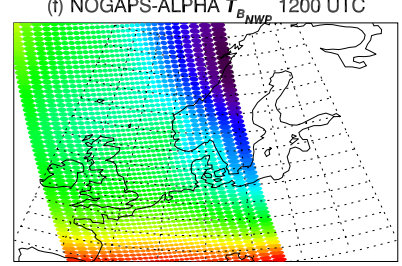

(h) NOGAPS-ALPHA $T_{B} \quad 2000$ UTC

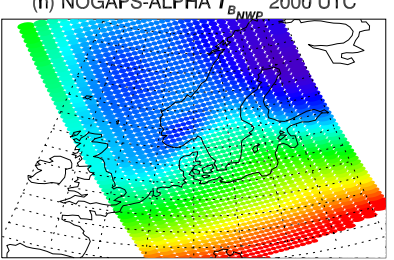

Fig. 5. Same presentation as Fig. 2, but now plotting synthetic Channel 9 brightness temperatures $T_{B_{\mathrm{NWP}}}\left(\hat{\lambda}_{j}, \hat{\phi}_{j}\right)$ computed from Eq. (2) using AMSU-A 3-D weighting functions, the actual AMSUA scanning patterns from Fig. 2 and the hourly NOGAPS-ALPHA temperature hindcast field $T(\hat{\lambda}, \hat{\phi}, Z)$ closest in time to each measurement.

fields to suppress gridpoint noise. Figure 6 plots maps of $T_{B}^{\prime}\left(\hat{\lambda}_{j}, \hat{\phi}_{j}\right)$ extracted in this way from the corresponding raw radiances in Fig. 2.

At $~ 01: 16$ UTC and 02:26 UTC (panels a and b in Fig. 6), the perturbation maps are essentially featureless. They show what appear to be small-amplitude artifacts from incomplete removal of background radiance structure, with peak amplitudes no larger than $\sim 0.2-0.25 \mathrm{~K}$. These values are in the range of the absolute AMSU-A noise floor values of $\sim 0.15$ $0.25 \mathrm{~K}$ (Mo, 1996; Lambrigtsen, 2003; Wu, 2004; Eckermann and $\mathrm{Wu}, 2006$ ), although our $3 \times 3$ point smoothing should reduce the noise floor in these maps by a factor of 3. Thus there appears to be little or no wave-like structure imaged in the Channel 9 radiances over Scandinavia at these times.

At 06:50 UTC during a NOAA-15 overpass, we see in Fig. $6 \mathrm{c}$ the first suggestions of a resolved wave-like oscillation in the radiance perturbation maps over southern Scandi-
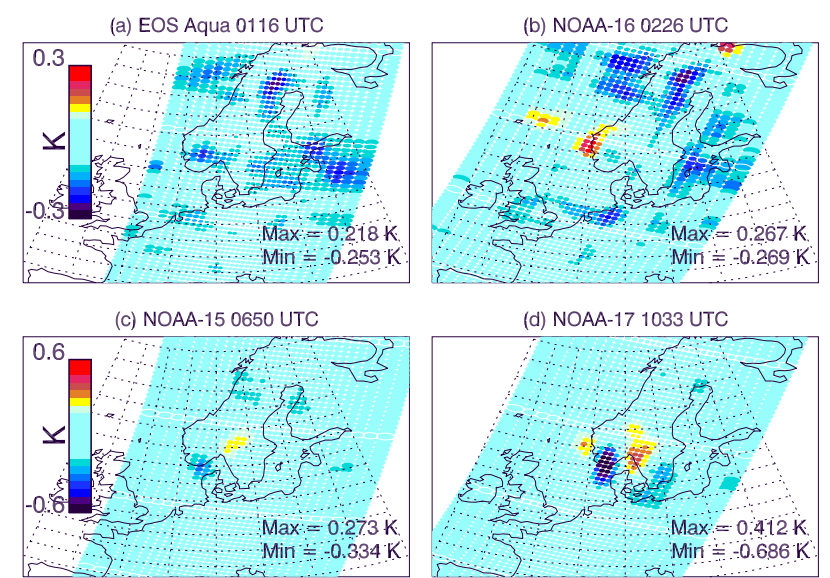

(d) NOAA-17 1033 UTC

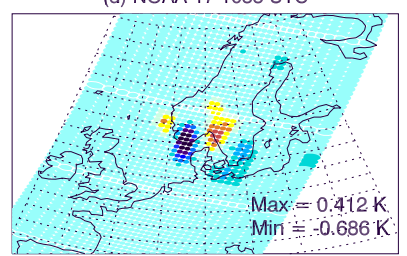

(e) NOAA-16 1221 UTC

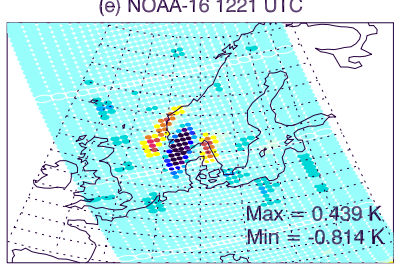

(f) EOS Aqua 1229 UTC

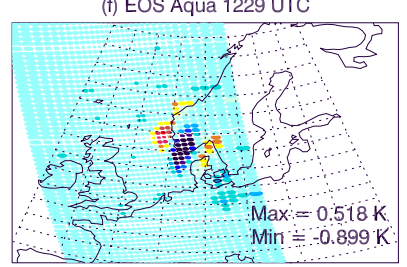

(g) NOAA-15 1641 UTC

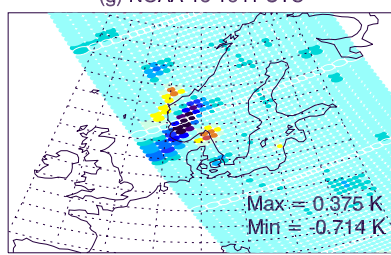

(h) NOAA-17 2023 UTC

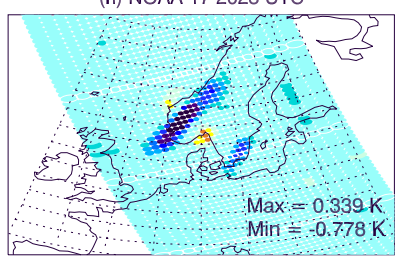

Fig. 6. Similar presentation to Fig. 2, but showing brightness temperature perturbations $T_{B}^{\prime}\left(\hat{\lambda}_{j}, \hat{\phi}_{j}\right)$ in Kelvin (see color bars). For panels (a) and (b), the range is $\pm 0.3 \mathrm{~K}$, whereas for panels (c-h) the color bar range is $\pm 0.6 \mathrm{~K}$. Maximum and minimum values for each map are shown in the lower-right portion of each panel.

navia (note the change in color scale from $\pm 0.3 \mathrm{~K}$ to $\pm 0.6 \mathrm{~K}$ in the maps at this time). In the subsequent AMSU-A overpasses at 10:33 UTC, 12:21 UTC and 12:29 UTC, this oscillation grows in amplitude to a maximum absolute peak perturbation of $\sim 0.9 \mathrm{~K}$ in the 12:29 UTC measurement from Aqua. In the final two measurements at 16:41 UTC and 20:23 UTC, the amplitude of the oscillation weakens slightly but also changes horizontal structure, attaining a longer wavelength that is aligned differently and has a packet width that is noticeably more elongated in the along-phase direction.

Figure $7 \mathrm{~b}$ plots brightness temperature perturbations along the horizontal trajectory in Fig. 7a for all 8 satellite overpasses. The 01:16 UTC curve lies near nominal noise floors, whereas the 02:26 UTC curve shows a peak at $100 \mathrm{~km}$ just above the nominal noise floor, indicating the initial presence of a weak wavelike oscillation. By 06:50 UTC an oscillation just above the noise is evident, which grows in amplitude 
while maintaining the same wavelength and phase out to 12:29 UTC. The wavelength along this trajectory is $\sim 400$ $500 \mathrm{~km}$, with slight increases by 16:41 UTC and 20:23 UTC.

\subsection{NWP model fields}

To isolate gravity wave perturbations from temperature fields generated by any one of our three NWP models, we use algorithms similar to those just described and applied to the AMSU-A radiances. First, the three-dimensional temperature fields at a given model time were regridded vertically from their terrain-following model coordinates to a common high-resolution set of constant pressure surfaces to yield a 3-D temperature field $T(\hat{\lambda}, \hat{\phi}, p)$, where $p$ is pressure. A background temperature field $\bar{T}(\hat{\lambda}, \hat{\phi}, p)$ was computed at each pressure level using a two-dimensional running average with a width of $\sim 600-650 \mathrm{~km}$. The precise width of this averaging window varied slightly from model to model, due to the different horizontal gridpoint resolutions $\Delta h$ and the resulting integer number of gridpoints $n$ needed to yield an averaging window $n \Delta h$ within this $600-650 \mathrm{~km}$ range.

Perturbations were derived as

$T^{\prime}(\hat{\lambda}, \hat{\phi}, p)=T(\hat{\lambda}, \hat{\phi}, p)-\bar{T}(\hat{\lambda}, \hat{\phi}, p)$.

The upper two rows of Fig. 8 plot $T^{\prime}(\hat{\lambda}, \hat{\phi}, p)$ fields at $p=90 \mathrm{hPa}$ from the three NWP models for $+24 \mathrm{~h}$ forecasts initialized on 13 January 2003 at 12:00 UTC, valid at 12:00 UTC on 14 January. They show a mountain wave oscillation over southern Scandinavia with a geographical extent and phase structure very similar to the 12:00 UTC AMSU-A brightness temperature perturbations in Figs. 6e and $\mathrm{f}$.

The bottom panels in Fig. 8 plot altitude cross sections of the temperature fields along the horizontal line plotted as the black curve in the panels above, which is the same trajectory used in Fig. 7a. Each NWP model produces a similar-looking mountain wave temperature oscillation that grows in amplitude with altitude up to $10 \mathrm{hPa}$ and beyond. The horizontal wavelength $\lambda_{h}$ is $\sim 400-500 \mathrm{~km}$ and the vertical wavelength $\lambda_{z}$ is $\sim 12 \mathrm{~km}$. The vertical range of the AMSU-A Channel 9 radiance acquisition through this wave structure is depicted in Fig. 8j using the 1-D vertical weighting functions for the near-nadir and far off-nadir scan angles from Fig. $1 b$.

The most obvious difference among the three model fields is in the wave amplitudes. At $90 \mathrm{hPa}$, NOGAPS-ALPHA yields peak amplitudes $T_{\text {PEAK }} \sim 4.5 \mathrm{~K}$, ECMWF IFS yields $T_{\text {PEAK }} \sim 6 \mathrm{~K}$, and COAMPS yields $T_{\text {PEAK }} \sim 7 \mathrm{~K}$. This increasing trend in wave amplitudes is consistent with increases in horizontal and vertical model resolution. Since the very smallest resolved scales in NWP models have little predictive skill (Lander and Hoskins, 1997; Davies and Brown, 2001), NWP models smooth their gridscale orography (Derber et al., 1998; Webster et al., 2003) and apply scale-selective numerical damping to their prognostic fields (Skamarock, 2004) to suppress these smallest scales. As a result, only at horizontal wavelengths greater than $\sim 6-10$ times the minimum

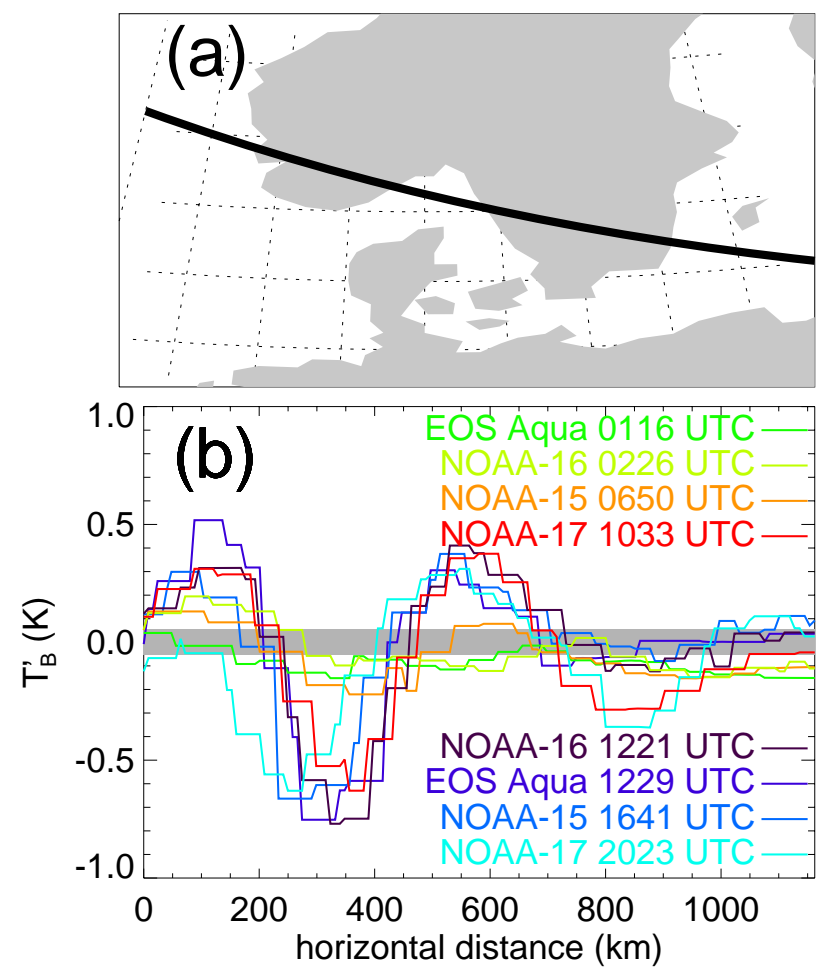

Fig. 7. Panel (b) plots AMSU-A brightness temperature perturbations along the horizontal trajectory plotted in (a), for all 8 overpasses plotted in Fig. 6. Gray strip in (b) marks the range $\pm 0.16 / 3 \mathrm{~K}$, the nominal noise-limited detection threshold after $3 \times 3$ point smoothing (Lambrigtsen, 2003).

horizontal gridpoint resolution $\Delta h$ do waves appear in these models without significant attenuation of their amplitudes (Davies and Brown, 2001; Skamarock, 2004). Vertical resolution differences in Fig. 1a also contribute, though previous studies suggest they are secondary to horizontal resolution for gravity waves in the extratropics so long as the vertical wavelength is sufficiently long (e.g., O'Sullivan and Dunkerton, 1995; Hamilton et al., 1999).

Previous studies of Scandinavian stratospheric mountain waves in global and mesoscale models have shown that the resolved wave amplitudes in the global model can be underestimated by anywhere up to $50-80 \%$. Hertzog et al. (2002) analyzed a stratospheric mountain wave over southern Scandinavia with a much shorter horizontal wavelength than here $\left(\lambda_{h} \sim 200 \mathrm{~km}\right)$ and a slightly shorter vertical wavelength $\left(\lambda_{z} \sim 10 \mathrm{~km}\right)$. While the estimated wave amplitude at $\sim 20 \mathrm{hPa}$ was $\sim 9 \mathrm{~K}$, the wave resolved in the ECMWF IFS $\mathrm{T}_{\mathrm{L}}$ 319L60 analyses had an amplitude of only $1.5 \mathrm{~K}$ and the horizontal wavelength was overestimated. $\mathrm{T}_{\mathrm{L}} 319$ corresponds to $\Delta h$ of $\sim 60 \mathrm{~km}$ on the N160 reduced linear Gaussian grid. Since this $\lambda_{h} \sim 200 \mathrm{~km}$ wave spans only $3-$ 4 ECMWF gridpoints, it is not surprising that its amplitude was significantly underestimated (Skamarock, 2004). 

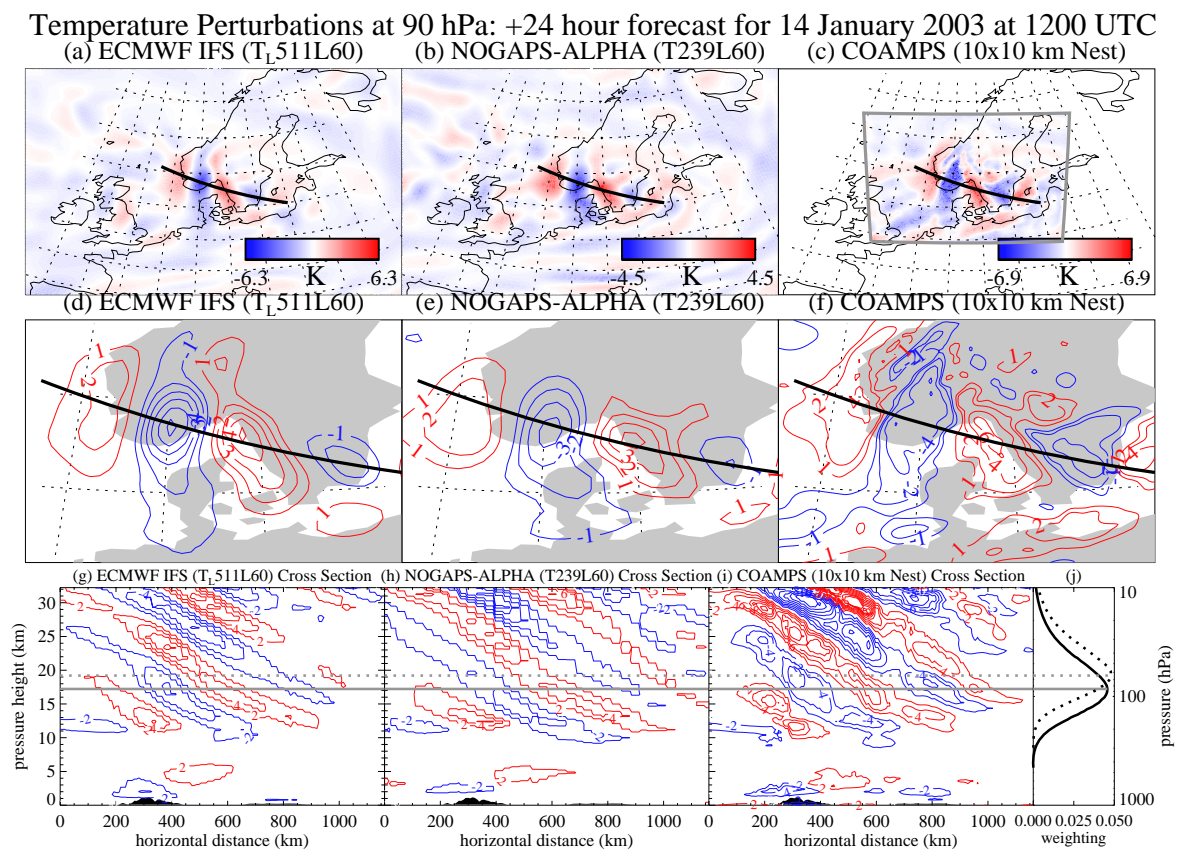

Fig. 8. Top row plots temperature perturbations $T^{\prime}(\hat{\lambda}, \hat{\phi}, p)$ at $p=90 \mathrm{hPa}$ extracted from $+24 \mathrm{~h}$ forecasts from ECMWF IFS (left column), NOGAPS-ALPHA (middle column) and COAMPS (right column) runs, using a similar map range to AMSU-A brightness temperature perturbations in Fig. 6. See color bar in the lower-right corner of each panel for temperature range. Middle row plots same fields, but now focused over southern Scandinavia. Contour interval is $1 \mathrm{~K}$. Bottom row of plots shows altitude contours of $T^{\prime}(\lambda, \phi, p)$ along the horizontal cross section plotted as black curve in the panels above. Negative (cold) temperature anomalies are blue, positive (warm) temperature anomalies are red, and the contour interval is $2 \mathrm{~K}$ (zero contour is omitted). Cross sections of topographic surface elevations are shaded in gray. Panel (j) replots AMSU-A Channel 9 1-D vertical weighting functions from Fig. 1 b.

A mountain wave with wavelengths closer to the current example occurred over northern Scandinavia on 26 January 2000: NWP forecasts yielded $\lambda_{h} \sim 400 \mathrm{~km}, \lambda_{z} \sim 10 \mathrm{~km}$ and $T_{\text {PEAK }} \sim 9 \mathrm{~K}$ at $30 \mathrm{hPa}$ (Dörnbrack et al., 2002; Fueglistaler et al., 2003; Eckermann et al., 2006). Eckermann et al. (2006) found that the wave temperature amplitude in the $\mathrm{T}_{\mathrm{L}}$ 319L60 ECMWF IFS forecast fields was 50\% lower than in a mesoscale model run (see also Fueglistaler et al., 2003). In this case, the horizontal wavelength $\lambda_{h} \sim 400 \mathrm{~km}$ spans around 6-7 ECMWF gridpoints, bringing it into the $6 \Delta h-$ $10 \Delta h$ transition zone where Skamarock (2004) found that dynamics were resolved but somewhat suppressed in energy.

Our $\lambda_{h} \sim 400-500 \mathrm{~km}$ mountain wave in the $\Delta h=10 \mathrm{~km}$ nested COAMPS run spans 40-50 horizontal gridpoints. According to Skamarock (2004), COAMPS should accurately simulate this wave, and thus for now we will take its simulated wave amplitude to represent the true wave amplitude. The $\mathrm{T}_{\mathrm{L}} 511$ ECMWF spectral resolution corresponds to $\Delta h \sim 40 \mathrm{~km}$ on the reduced N256 linear Gaussian grid, making our $\lambda_{h} \sim 400-500 \mathrm{~km}$ wave a $10 \Delta h$ oscillation in these fields and placing it at the high end of the 6-10 $\Delta h$ transition zone where amplitudes are not greatly suppressed (Skamarock, 2004). A comparison of Figs. 8a and c bears this out. NOGAPS-ALPHA's T239 spectral resolution yields a gridpoint resolution on the $720 \times 360$ quadratic Gaussian grid of $\sim 55 \mathrm{~km}$ at the equator, though the intrinsic resolution to zonal wavelengths is nearer $80 \mathrm{~km}$ at the equator. This places our wave in NOGAPS-ALPHA fields somewhere in the 5$9 \Delta h$ range where we expect some significant amplitude underestimatation (Skamarock, 2004; Eckermann et al., 2006), consistent with amplitude differences between Figs. 8a and c.

\subsection{Suborbital validation of NWP model fields}

For a more direct and objective assessment of the fidelity of the gravity waves in these NWP fields, we now compare them directly to suborbital measurements of the lower stratosphere over southern Scandinavia on 14 January 2003.

\subsubsection{Radiosonde}

Figure 9 plots the estimated 3-D trajectory of the routine RS80 Vaisala radiosonde sounding made from Stavanger/Sola $\left(58.86^{\circ} \mathrm{N}, 5.65^{\circ} \mathrm{E}\right)$ on 14 January 2003 at 12:00 UTC. The calculation uses the radiosonde horizontal winds from this ascent and assumes passive frictionless advection of the balloon as it ascends at a constant assumed velocity of $5 \mathrm{~m} \mathrm{~s}^{-1}$ (Lane et al., 2000). The inferred ground trajectory (dotted gray curve in Fig. 9) takes this balloon through the regions of largest stratospheric gravity wave 
amplitudes evident in the NWP model fields in Fig. 8. Assuming an ontime 12:00 UTC launch, we estimate the balloon reached $90 \mathrm{hPa}$ just before 13:00 UTC.

The contours in Fig. 9 show the NOGAPS-ALPHA $+24 \mathrm{~h}$ (12:00 UTC) zonal winds at $59.75^{\circ} \mathrm{N}$. They reveal strong surface westerlies of $\sim 20 \mathrm{~m} \mathrm{~s}^{-1}$ that increase with height to a tropopause jet stream exceeding $60 \mathrm{~m} \mathrm{~s}^{-1}$, and a waveinduced horizontal velocity oscillation of around $\pm 10 \mathrm{~m} \mathrm{~s}^{-1}$ in the stratosphere superimposed on mean westerlies of 30$40 \mathrm{~m} \mathrm{~s}^{-1}$. The strong westerly flow at all altitudes is consistent with surface forcing of quasi-stationary mountain waves and free propagation of those waves into the stratosphere (i.e., no critical level). The wave phase lines slope downward on progressing eastward, as in the temperature cross sections in Figs. 8g-i, consistent with a quasi-stationary mountain wave propagating upward and westward in this eastward flow.

Observational studies often assume that gravity wave fluctuations in radiosonde data can be interpreted as a purely vertical profile through the 3-D wave field directly above the launch site. Here, however, the strong westerlies advect the balloon substantial distances to the east. Figure 9 shows rather clearly in this case that the radiosonde samples a significantly different wave structure along its oblique ascent trajectory than the purely vertical profile directly above Stavanger, an issue highlighted in some previous observational studies of mountain waves using radiosonde data (e.g., Shutts et al., 1988; Lane et al., 2000). Thus our model-data comparison in Fig. 10 compares the radiosonde zonal winds $U$, meridional winds $V$ and temperatures $T$ with corresponding 12:00 UTC fields from the 3 NWP model runs that were sampled along the 3-D radiosonde trajectory in Fig. 9.

The NWP wind and temperature profiles in Fig. 10 are close to the radiosonde data at all altitudes. The stratospheric wave oscillation is most prominent in the zonal winds in Fig. 10a. The model fields reproduce its amplitude and phase quite well, given the uncertainties in the actual balloon trajectory, model errors and slight time mismatches between NWP fields and the radiosonde. Though the wave appears more weakly in the meridional wind and temperature profiles, the NWP fields match the amplitude and phase structure well in these profiles too.

The upper-level radiosonde temperatures in Fig. 10c are extremely cold. The final radiosonde measurement of $179.6 \mathrm{~K}$ near $19 \mathrm{hPa}$ is only $\sim 1 \mathrm{~K}$ warmer than the record low stratospheric radiosonde temperature of $178.6 \mathrm{~K}$ reported by Dörnbrack et al. (1999) from 35 years of soundings from Sodankylä $\left(67.4^{\circ} \mathrm{N}, 26.7^{\circ} \mathrm{E}\right)$ in northern Finland (though this record value was subsequently eclipsed in January 2001: see Kivi et al., 2001). Since Stavanger/Sola lies some $8.5^{\circ}$ equatorward of Sodankylä, this low temperature is unusual and ordinarily might be questioned given that it was the final measurement acquired just prior to the balloon bursting. However, the NWP model profiles computed along its ascent trajectory in Fig. 10c strongly suggest that the data here are

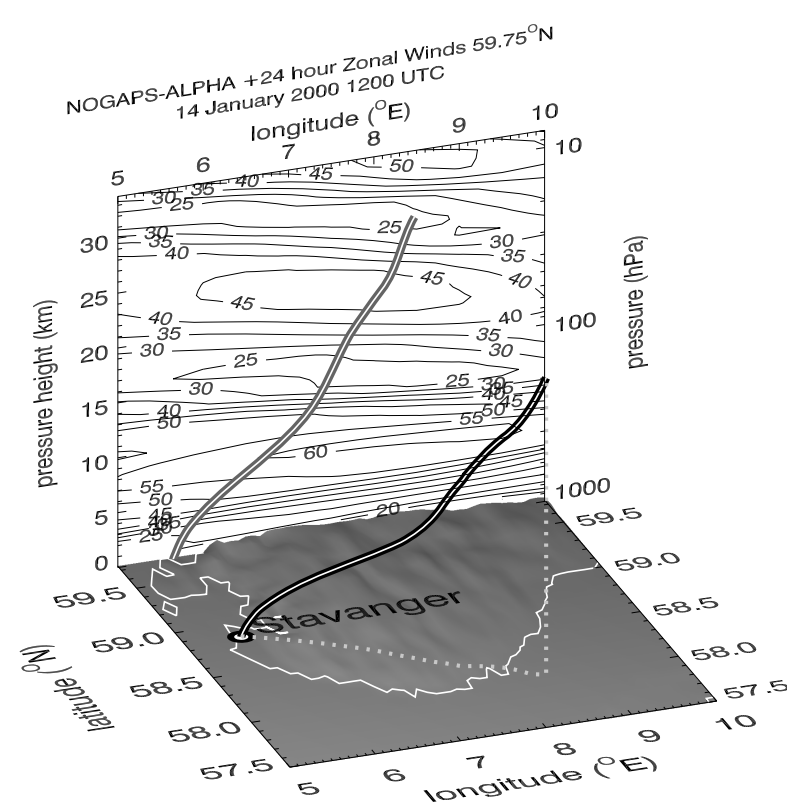

Fig. 9. Solid black curve with white stripe shows the estimated 3-D trajectory of the radiosonde launched from Stavanger on 14 January 2003 at 12:00 UTC. Shaded 3-D surface shows topographic elevations from the ETOPO5 database. Contours show zonal winds in $\mathrm{m} \mathrm{s}^{-1}$ (positive values are eastward) at $59.75^{\circ} \mathrm{N}$ from the $+24 \mathrm{~h}$ NOGAPS-ALPHA hindcast. The latitude-height projection of the $3-\mathrm{D}$ radiosonde trajectory is plotted in gray with white stripe.

reliable, and that these cold temperatures result from passage of the balloon through the cooling phase of a large-amplitude stratospheric mountain wave.

\subsubsection{NASA DC-8 flight}

Red curves in Fig. 10c show that these very cold temperatures at $20 \mathrm{hPa}$ lie below the frost point temperature $T_{\mathrm{ICE}}$, which should cause type II (ice) PSCs to form here if nucleation material is present. Aerosol lidar data acquired from a NASA DC-8 flight on this day allow us to test this inference, and to validate the NWP model fields further.

During January 2003 the DC-8 was operating from Kiruna airport $\left(67.8^{\circ} \mathrm{N}, 20.3^{\circ} \mathrm{E}\right)$ in northern Sweden, in support of NASA's second SAGE III Ozone Loss and Validation Experiment (SOLVE II; see McCormack et al., 2004). The cold synoptic stratospheric conditions and stratospheric mountain wave activity over southern Scandinavia on 14 January 2003 were both forecast several days beforehand using ECMWF IFS fields and the NRL Mountain Wave Forecast Model (MWFM), extending similar in-field wave forecasting efforts inaugurated for SOLVE during 1999-2000 and reported by Eckermann et al. (2006).

NAVDAS $925 \mathrm{hPa}$ geopotential heights at 12:00 UTC in Fig. 11a show that mountain wave generation on 14 January was driven by a compact polar low whose core moved 


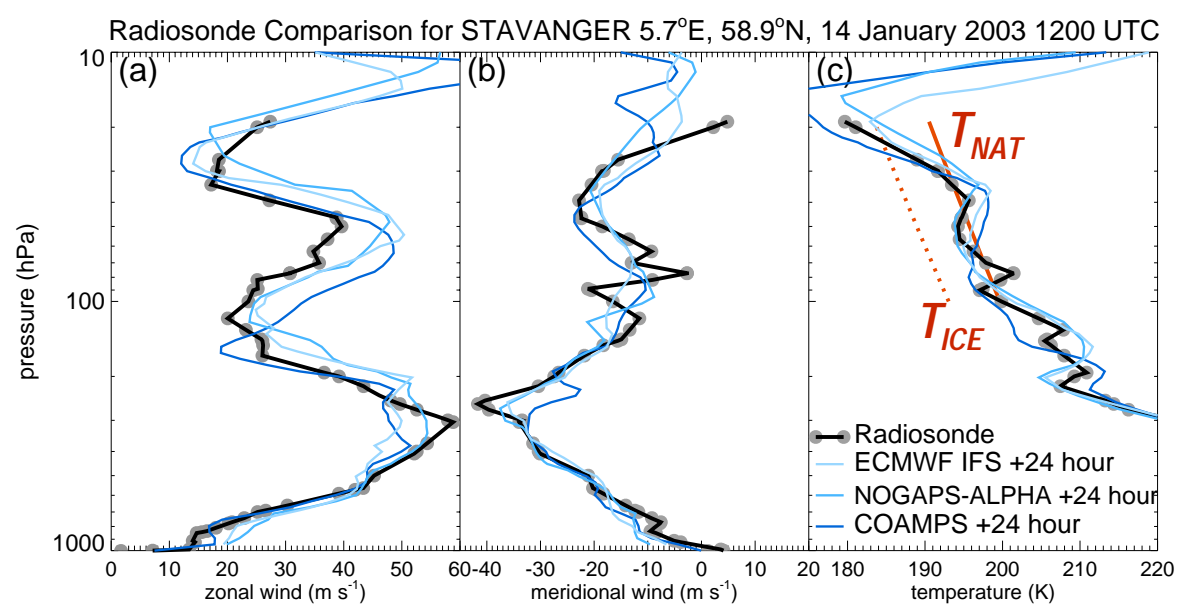

Fig. 10. Gray circles connected by solid black curve show data acquired from the 14 January 2003 12:00 UTC radiosonde sounding from Stavanger: (a) zonal winds; (b) meridional winds; (c) temperatures. Blue curves show output from the $+24 \mathrm{~h}$ ECMWF IFS operational forecast, the $+24 \mathrm{~h}$ NOGAPS-ALPHA hindcast, and the $+24 \mathrm{~h}$ COAMPS hindcast, all valid for 12:00 UTC on 14 January 2003, computed along the 3-D radiosonde trajectory in Fig. 9. Red curves in (c) show nominal threshold temperatures $T_{\mathrm{ICE}}$ and $T_{\mathrm{NAT}}$ for formation of ice and nitric acid trihydrate, respectively, assuming typical stratospheric values of 5 ppmv of water vapor and 10 ppbv of nitric acid (Hanson and Mauersberger, 1988; Marti and Mauersberger, 1993).

rapidly eastward across central Scandinavia, bringing with it strong surface westerly flow across the southern Scandinavian Mountains. The near-zero surface winds over central Scandinavia in the core of the low and weak surface easterlies across northern Scandinavia account for the confinement of the stratospheric wave activity to the south, since little mountain wave activity is forced over central Scandinavia, while any waves generated to the north are absorbed at upper tropospheric critical levels as the flow transitions from surface easterlies to upper tropospheric and stratospheric westerlies.

The SOLVE II forecasts for 14 January predicted PSCs forming within the cold phases of mountain waves over southern Scandinavia. Based on this forecast guidance, a DC-8 flight from Kiruna was devised containing a southward leg to fly beneath these forecast wave PSCs and profile them with onboard lidars. The final DC-8 flight track is plotted in blue in Fig. 11a, with filled circles marking every $30 \mathrm{~min}$ along the flight segment from 06:00-09:30 UTC. The radiosonde trajectory from Fig. 9 is plotted in red. We see that the DC- 8 flew beneath the cold $20 \mathrm{hPa}$ stratospheric region sampled at the end of the radiosonde trajectory just after 07:00 UTC, some 5-6h before the radiosonde sampled this region. From the AMSU-A data in Fig. 6c, the mountain wave appeared to be present in this region at 07:00 UTC when the DC-8 arrived, but had a weaker amplitude than at the time of the radiosonde intercept at 12:00-13:00 UTC.

Figure $11 \mathrm{~b}$ plots $S_{1064}$ from the GSFC/LaRC lidar returns (see Sect. 2.2) from 06:00 UTC to 09:30 UTC, a flight segment marked with the thicker blue line in Fig. 11a. Extensive PSC aerosol was measured in a number of thin tilted layers in the $20-26 \mathrm{~km}$ altitude range. Isolated yellow-red regions where $S_{1064}$ is $\sim 50-200$ likely indicate ice (type II) PSCs.

Figure $11 \mathrm{c}$ plots temperatures $T\left(\hat{\lambda}, \hat{\phi}, Z_{\text {geo }}\right)$ from the NOGAPS-ALPHA $+19 \mathrm{~h}$ hindcast (valid at 07:00 UTC) along this DC-8 flight track. Here we have profiled the fields as a function of model geopotential height $Z_{\text {geo }}$ rather than pressure height $Z$, to permit more direct comparison with the geometric altitude registration of the lidar data. The coldest temperature contours $\leq 190 \mathrm{~K}$ are color coded, and correlate impressively in altitude and variation with flight time with the lidar data in the panel above. In particular the isolated region of large $S_{1064}$ at $25 \mathrm{~km}$ at 07:00 UTC is colocated with a compact region of the coldest NOGAPS-ALPHA temperatures of $\sim 184 \mathrm{~K}$, plotted as red contours. This $25 \mathrm{~km}$ altitude corresponds to pressures of $\sim 18-20 \mathrm{hPa}$ (see grey contours in Fig. 11d). From Fig. 11a we see that this isolated type II PSC layer measured at 07:00 UTC in panel (b) occurs at the same geographical location intercepted 5-6 $\mathrm{h}$ later by the radiosonde, which measured very cold temperatures $T<T_{\mathrm{ICE}}$ in Fig. 10c that should form ice PSCs. Thus the radiosonde, lidar and NWP temperature data all cross-validate at this location.

AROTAL Rayleigh temperature profiles are also available from this flight. However, the presence of sunlight and PSC aerosol yielded noisy retrieved temperatures with large errors or data gaps within and below the PSC layers. Thus we focus on a 5 min flight interval starting at 06:49 UTC when $S_{1064}$ in Fig. $11 \mathrm{~b}$ is small at all altitudes just prior to the intercept of the ice PSC at $\sim 07: 00$ UTC. AROTAL temperatures for this period are plotted in Fig. 12 alongside the NOGAPS-ALPHA and ECMWF IFS temperature profile closest in time and location. The grey region in Fig. 12 marks altitudes where PSC 


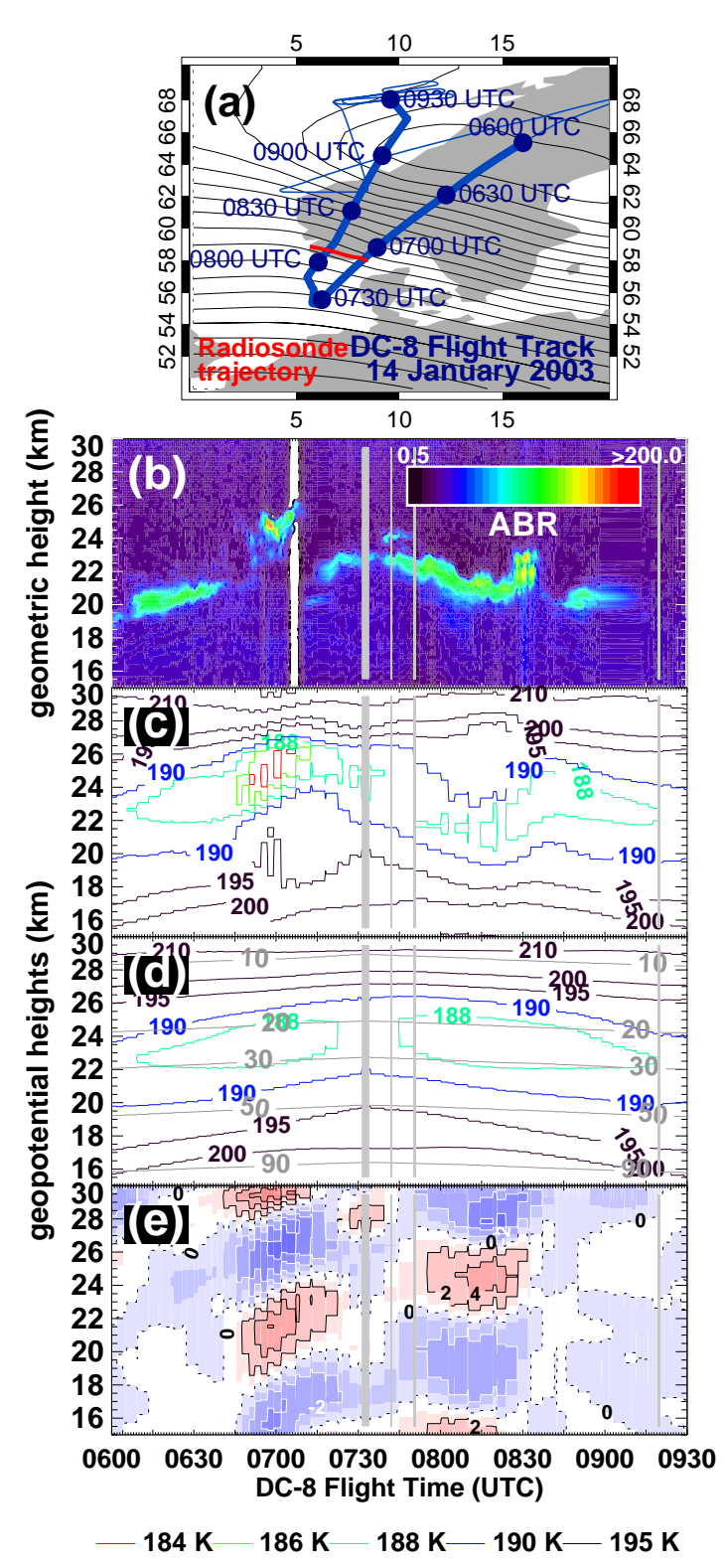

Fig. 11. (a) Blue curves show DC-8 flight of 14 January 2003, with period from 06:00-09:30 UTC highlighted with thicker curve and 30 min markers. Red curve shows horizontal radiosonde trajectory from Fig. 9. Contours show 12:00 UTC $925 \mathrm{hPa}$ NAVDAS analyzed geopotential heights. (b) $S_{1064}$ from GSFC/LaRC aerosol lidar from 06:00-09:30 UTC, derived as 8 point averages of the raw data (4 points in time, 2 points in height). Gray strips omit data where DC- 8 turned in (a) to roll angles $>5^{\circ}$ which tilted the lidar beam off zenith. Color bar scale is logarithmic. (c) Temperatures $T$ along DC-8 flight track from NOGAPS-ALPHA $+19 \mathrm{~h}$ forecast, valid at 07:00 UTC, plotted versus model geopotential height. Contour color scale is shown beneath panel (e). (d) as for (c) but plotting mean temperatures $\bar{T}$. Gray contours show pressure surfaces in $\mathrm{hPa}$. (e) as for (c) but plotting temperature perturbations $T^{\prime}$, the difference field between (c) and (d). Contour interval is $2 \mathrm{~K}$, positive values are red and negative values are blue.

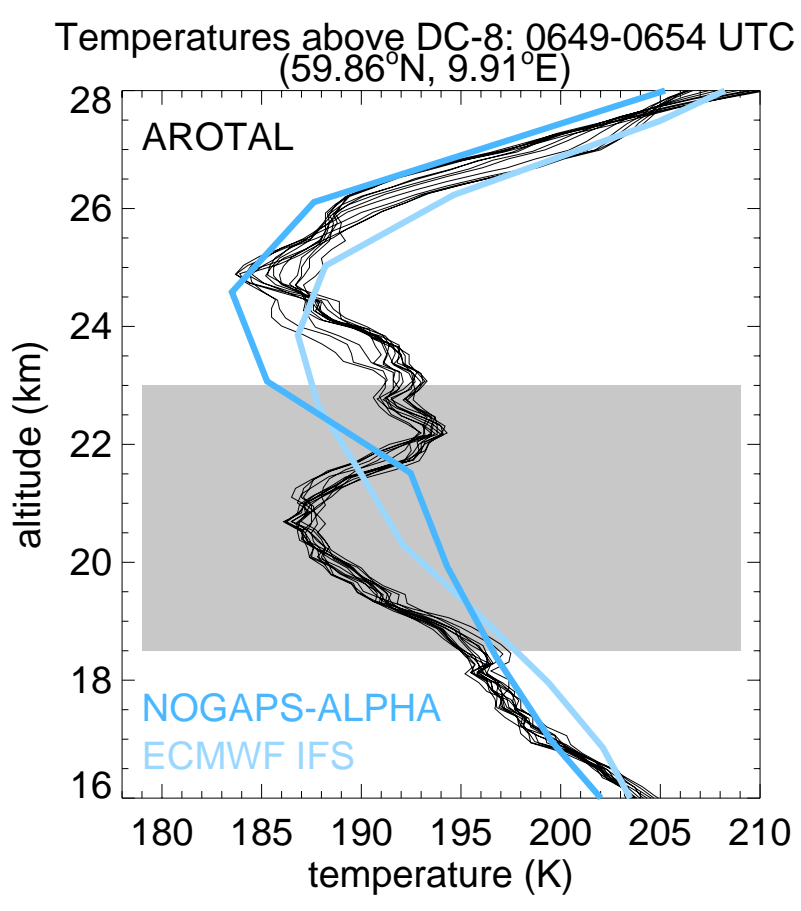

Fig. 12. Black curves show raw AROTAL Rayleigh temperatures acquired from the DC-8 on 14 January from 06:49-06:54 UTC. Blue curves show temperature profiles at the closest horizontal gridpoint to this flight segment from the NOGAPS-ALPHA $+19 \mathrm{~h}$ hindcast (valid at 07:00 UTC) and the ECMWF IFS $+18 \mathrm{~h}$ forecast (valid at 06:00 UTC). Gray strip shows estimated altitudes where the AROTAL temperature retrieval is significantly contaminated by PSC aerosol layers.

layers were observed earlier in the flight in Fig. 11b, and thus contain aerosol which can contaminate the retrieval. Indeed, the cold temperature "biteout" in the data at $21 \mathrm{~km}$ in Fig. 12 resembles the structure of the PSC-contaminated retrieved Rayleigh temperature profile shown in Fig. 7 of Burris et al. (2002b). Thus we view AROTAL temperatures in this region as suspect. Above this grey strip $(Z \geq 23 \mathrm{~km})$, we assume more PSC-free air that yields a more accurate retrieved temperature. Specifically, at $25 \mathrm{~km}$ the AROTAL temperatures drop to a minimum of $\sim 184 \mathrm{~K}$, which again agrees well with the NOGAPS-ALPHA temperatures in Figs. 11c and 12 and is consistent with the ice PSC encountered minutes later at this altitude by the DC- 8 .

We speculated that the mountain wave perturbations produced the very cold $20 \mathrm{hPa}$ temperatures in this region. To assess this, we split the NOGAPS-ALPHA temperature field into its component background field $\bar{T}(\hat{\lambda}, \hat{\phi}, p)$ and perturbation field $T^{\prime}(\hat{\lambda}, \hat{\phi}, p)$ from Eq. (4), and plot each in Figs. 11d and e, respectively, along the DC- 8 flight track. The background temperatures show a gently sloping layer of cold temperatures at $22-24 \mathrm{~km}$ that explains a small part of the large-scale PSC tilting evident in the aerosol data, but little 


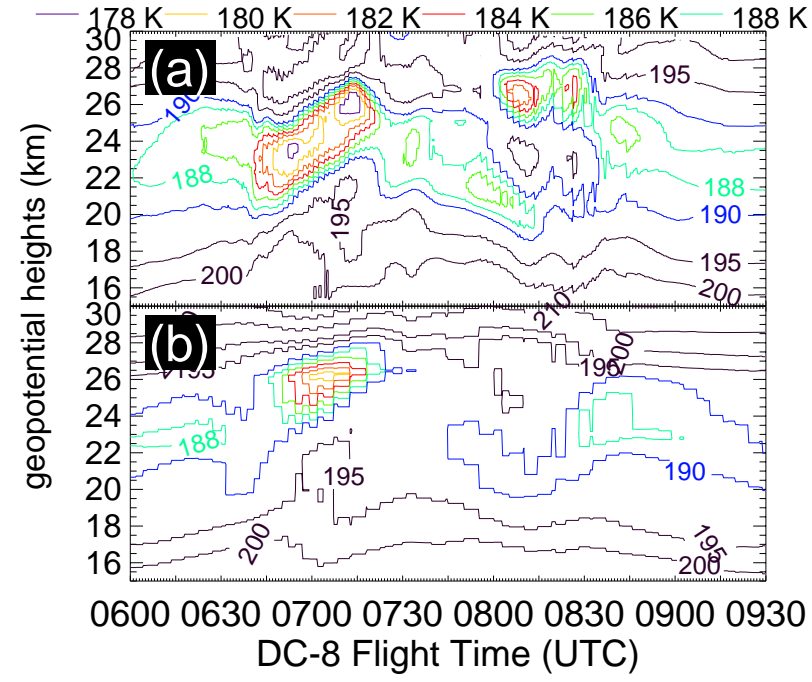

Fig. 13. Same presentation as in Fig. 11c, but profiling temperatures from (a) COAMPS $+19 \mathrm{~h}$ hindcast, valid at 07:00 UTC, and (b) NOGAPS-ALPHA $+24 \mathrm{~h}$ hindcast, valid at 12:00 UTC. Contour color scale is shown above panel (a).

else. Clearly the omitted wave component produces most of the observed structure in these PSC layers. The perturbation temperatures in Fig. 11e show that the ice PSC at 07:00 UTC is produced by a mountain wave-induced temperature perturbation that cools this region by about $6-8 \mathrm{~K}$. This then is clearly a mountain wave-induced ice PSC.

The minimum NOGAPS-ALPHA temperature in Figs. $11 \mathrm{c}$ and 12 of $\sim 184 \mathrm{~K}$ is at or just slightly above the $20 \mathrm{hPa}$ frost point temperature shown in red in Fig. 10c. That ice PSCs were measured here suggests that wave amplitudes were underestimated in the NOGAPS-ALPHA run, consistent with our earlier inferences based on its T239L60 resolution. To assess this, Fig. 13a plots corresponding 07:00 UTC temperatures from the COAMPS run, which show a thicker layer of much colder temperatures at 07:00 UTC due to larger wave amplitudes in this higher resolution model.

At 12:00-13:00 UTC when the radiosonde entered this region, the minimum 12:00 UTC NOGAPS-ALPHA temperature along the radiosonde trajectory in Fig. 10c was $\sim 180 \mathrm{~K}$, significantly colder than the $184 \mathrm{~K}$ in Fig. 11c. This suggests that the wave in the NOGAPS-ALPHA run grew significantly in amplitude from 07:00 UTC to 12:00 UTC, consistent with what the AMSU-A data in Fig. 6 appear to show. To assess this, Fig. 13b plots corresponding NOGAPSALPHA temperatures along the DC-8 flight trajectory using the $+24 \mathrm{~h}$ forecast fields, valid at 12:00 UTC. We see that the minimum temperatures are now $180 \mathrm{~K}, 4 \mathrm{~K}$ cooler than in Fig. 11c, indicating a growth in peak wave amplitude of $\sim 4 \mathrm{~K}$ from 07:00 UTC to 12:00 UTC, and again consistent with the $179.2 \mathrm{~K}$ radiosonde temperature measured at $19 \mathrm{hPa}$ in Fig. 10c.

\section{Brightness temperature perturbations from forward modeled NWP temperature fields}

Having validated the NWP temperature fields against available suborbital data, we now insert these fields into Eq. (2) to derive anticipated AMSU-A Channel 9 brightness temperature perturbations, which we compare against the observed AMSU-A perturbations. This represents our approach to validating the gravity wave signals in AMSU-A Channel 9 radiances.

\subsection{Forward modeled NWP temperature perturbations}

We begin with direct forward modeling of the NWP wave temperature perturbation fields $T^{\prime}(\hat{\lambda}, \hat{\phi}, p)$ to yield a brightness temperature perturbation field

$$
\begin{array}{r}
T_{B_{\mathrm{NWP}}}^{\prime}\left(X_{j}, Y_{j}\right)=\iiint W_{j}\left(X-X_{j}, Y-Y_{j}, Z\right) \\
T^{\prime}(X, Y, Z) d X d Y d Z .
\end{array}
$$

Similar calculations for idealized 3-D wave temperature oscillations were performed by Eckermann and Wu (2006).

To facilitate direct comparisons with AMSU-A imagery, here we use the orbital scan geolocations from each AMSUA overpass to synthesize forward-modeled swath-scanned pushbroom images, using the algorithms outlined in Sect. 3.2 and the NWP $T^{\prime}(\hat{\lambda}, \hat{\phi}, p)$ field closest in time to each overpass. Final $T_{B_{\mathrm{NWP}}}^{\prime}\left(\hat{\lambda}_{j}, \hat{\phi}_{j}\right)$ maps incorporated the same $3 \times 3$ point smoothing applied to the AMSU-A perturbations in Fig. 6. Figure 14 plots resulting $T_{B_{\mathrm{NWP}}}^{\prime}\left(\hat{\lambda}_{j}, \hat{\phi}_{j}\right)$ fields for AMSU-A 12:21 UTC measurements from NOAA-16 (top row) and 12:29 UTC measurements from EOS Aqua (bottom row), based on 12:00 UTC ( $+24 \mathrm{~h}$ forecast) $T^{\prime}(\hat{\lambda}, \hat{\phi}, p)$ fields from ECMWF IFS, NOGAPS-ALPHA and COAMPS. The corresponding AMSU-A data from Fig. 6 are reproduced in the right panels of Fig. 14 for comparison.

The synthetic NWP $T_{B_{\mathrm{NWP}}}^{\prime}\left(\hat{\lambda}_{j}, \hat{\phi}_{j}\right)$ maps all show a wave oscillation over southern Scandinavia that matches the AMSU-A data well in location, horizontal extent, orientation and phase. In terms of amplitude, the ECMWF IFS amplitudes are close to the measured values. The NOGAPSALPHA amplitudes are smaller, consistent with expected underprediction of wave amplitudes in these T239L60 runs, as discussed in Sect. 5.2. The COAMPS amplitudes are fairly close to the EOS Aqua AMSU-A observations, but somewhat larger than the NOAA-16 AMSU-A observations.

Indeed, despite using the same 12:00 UTC $T^{\prime}(\hat{\lambda}, \hat{\phi}, p)$ fields, all the resulting $T_{B_{\mathrm{NWP}}}^{\prime}\left(\hat{\lambda}_{j}, \hat{\phi}_{j}\right)$ amplitudes in Fig. 14 are systematically larger for the NOAA-16 scan pattern than for the EOS Aqua scan pattern. This is despite the fact that the lower orbit altitude of EOS-Aqua compared to NOAA16 yields smaller horizontal footprints that should make EOS Aqua AMSU-A measurements slightly more sensitive to gravity waves of a given scale than those on the NOAA satellites (Eckermann and $\mathrm{Wu}, 2006$ ). 
(a) ECMWF IFS $T_{B_{\text {NWP }}} 1200$ UTC

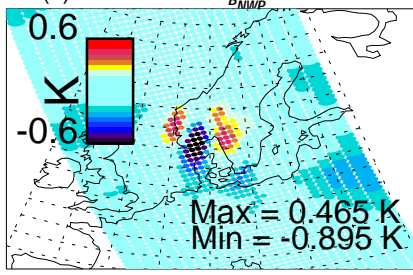

(e) ECMWF IFS $T_{B_{N W P}} 1200$ UTC

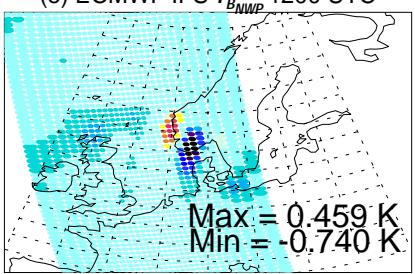

(b) NOGAPS-ALPHA $T_{B_{\text {NWP }}} 1200$ UTC

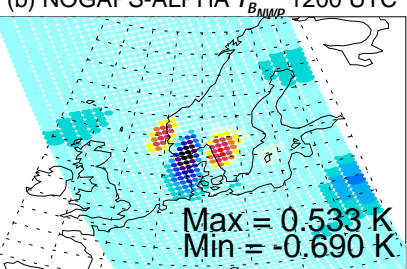

(f) NOGAPS-ALPHA $T_{B_{\text {NWP }}} 1200$ UTC

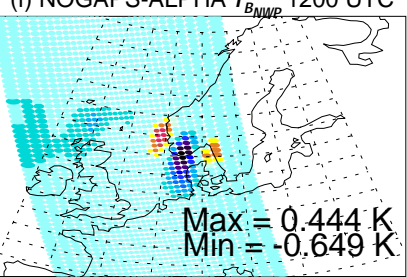

(c) COAMPS $T_{B_{N W P}}^{\prime} 1200$ UTC

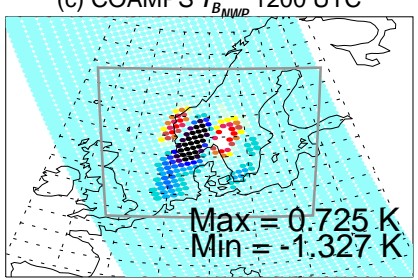

(g) COAMPS $T_{B_{\text {NWP }}}^{\prime} 1200$ UTC

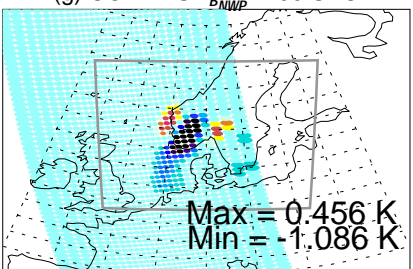

(d) AMSU-A NOAA-16 1221 UTC

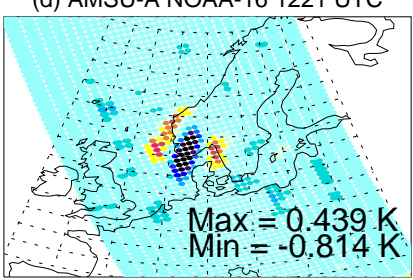

(h) AMSU-A EOS Aqua 1229 UTC

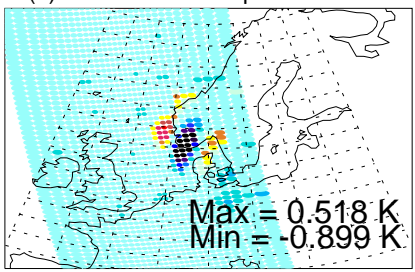

Fig. 14. Top row shows brightness temperature perturbations $T_{B_{\mathrm{NWP}}}^{\prime}\left(\hat{\lambda}_{j}, \hat{\phi}_{j}\right)$ computed from Eq. (5) using 12:00 UTC NWP temperature perturbation fields $T^{\prime}(\hat{\lambda}, \hat{\phi}, p)$ from (a) ECMWF IFS, (b) NOGAPS-ALPHA, and (c) COAMPS runs using AMSU-A scan pattern from the NOAA-16 12:21 UTC overpass. Actual brightness temperatures extracted from these AMSU-A measurements are replotted in (d) from Fig. 6e. Bottom row shows same sequence of plots for the 12:29 UTC EOS Aqua overpass data. Gray borders in (c) and (g) show the regional COAMPS domain. Color bar scale $( \pm 0.6 \mathrm{~K})$ is given at the top-left of panel (a). Maximum and minimum values for each map are shown in the lower-right portion of each panel.

The smaller EOS Aqua $T_{B_{\mathrm{NWP}}}^{\prime}\left(\hat{\lambda}_{j}, \hat{\phi}_{j}\right)$ amplitudes in Fig. 14 arise due to the height variation of the wave temperature amplitudes in the NWP models. As shown in the bottom row of Fig. 8, the wave temperature amplitudes in all 3 models decrease between $80-90 \mathrm{hPa}$ and $50-60 \mathrm{hPa}$. For example, the corresponding maximum ECMWF IFS amplitude at $60 \mathrm{hPa}$ is $4.8 \mathrm{~K}$ compared to the $6.3 \mathrm{~K}$ at $90 \mathrm{hPa}$ in Fig. 8a. The wave in the NOAA-16 12:21 UTC overpass data lies near the center of the scan pattern and so is observed by the near-nadir beams whose weighting functions peak near $80-90 \mathrm{hPa}$. Conversely, the wave is located towards the right edge of the EOS Aqua scan pattern, where it is observed by off-nadir beams which peak at higher altitudes (see Fig. 8j). The weaker NWP model temperature amplitudes at these higher altitudes lead to a weaker NWP brightness temperature perturbation for the EOS Aqua scan.

In contrast to the model fields, the observed AMSU-A perturbation amplitudes are slightly larger for the EOS Aqua overpass in Fig. 14h than for the NOAA-16 overpass in Fig. 14d. This suggests that, while the NWP models have captured the wave structure and mean wave amplitudes quite well, the actual vertical variation in wave amplitudes over the $50-90 \mathrm{hPa}$ range may have differed from the model predictions.

6.2 Perturbations isolated from forward modeled NWP temperatures

Next we perform more realistic forward modeling by using the raw NWP model temperature fields to simulate a bright- ness temperature field $T_{B_{\mathrm{NWP}}}\left(\hat{\lambda}_{j}, \hat{\phi}_{j}\right)$ using Eq. (2), as in Fig. 2. Then, we apply exactly the same data reduction algorithms to these brightness temperature fields that we applied to the AMSU-A brightness temperature data in Sect. 5.1, first deriving a background field $\bar{T}_{B_{\mathrm{NWP}}}\left(\hat{\lambda}_{j}, \hat{\phi}_{j}\right)$ and then, following Eq. (3), computing perturbation fields

$T_{B_{\mathrm{NWP}}}^{\prime}\left(\hat{\lambda}_{j}, \hat{\phi}_{j}\right)=T_{B_{\mathrm{NWP}}}\left(\hat{\lambda}_{j}, \hat{\phi}_{j}\right)-\bar{T}_{B_{\mathrm{NWP}}}\left(\hat{\lambda}_{j}, \hat{\phi}_{j}\right)$.

Finally, $3 \times 3$ point smoothing is applied to these perturbation fields. Differences between perturbation fields calculated using this method and those calculated in Sect. 6.1 provide some feel for how well the numerical data reduction methods in Sect. 5.1 isolate gravity wave perturbations from raw AMSU-A radiances.

Figure 15 plots NWP perturbation brightness temperatures calculated using this method for the same set of 12:00 UTC fields and AMSU-A scans shown in Fig. 14. Oscillatory structure that closely resembles the measurements (panels $\mathrm{d}$ and $h$ ) is reproduced in all the NWP-based radiance fields over southern Scandinavia. On comparing with corresponding panels in Fig. 14, we see that $T_{B_{\mathrm{NWP}}}^{\prime}\left(\hat{\lambda}_{j}, \hat{\phi}_{j}\right)$ amplitudes here are $\sim 10-25 \%$ smaller. Thus, wave perturbations are isolated well using these data reduction procedures, being only slightly suppressed in amplitude. ECMWF IFS amplitudes in Fig. 15 are slightly smaller than the measured values, and NOGAPS-ALPHA amplitudes are significantly smaller at the negative (cold) wave phase. COAMPS amplitudes are very similar to the EOS Aqua observations, but slightly larger than the NOAA-16 observations. More precise comparisons with data are provided shortly. 

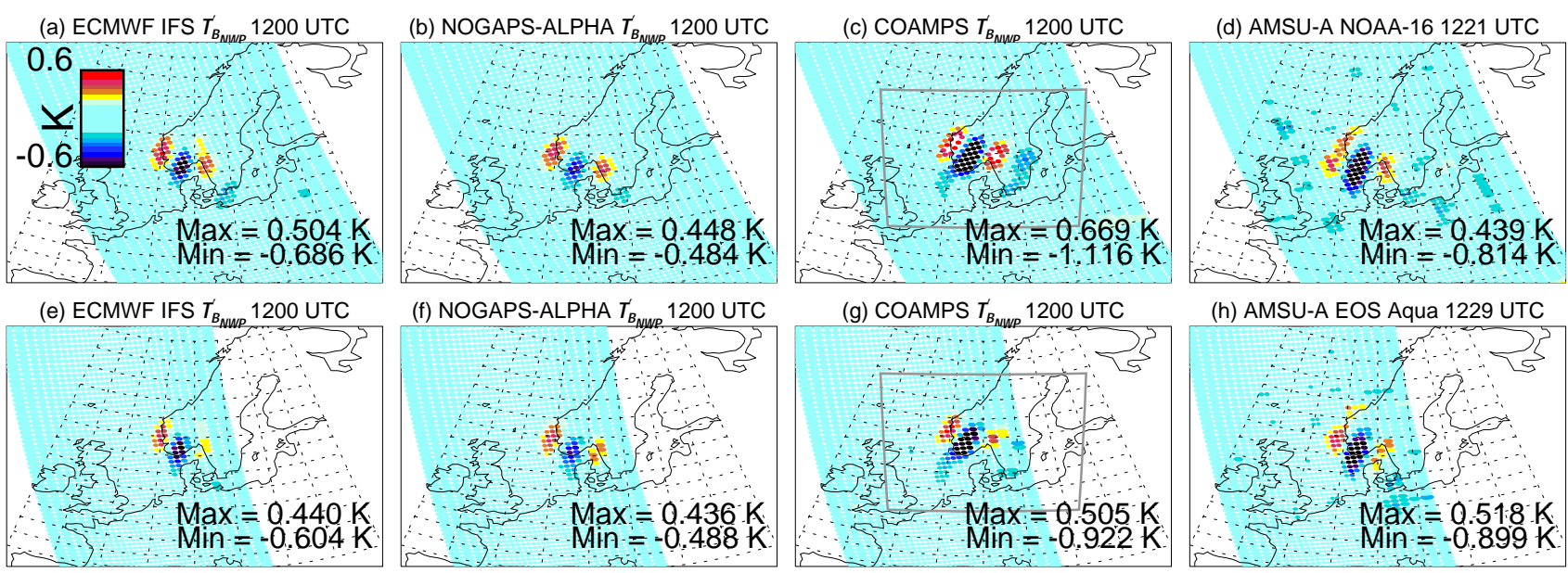

(g) COAMPS $T_{B_{\text {NWP }}}^{\prime} 1200$ UTC
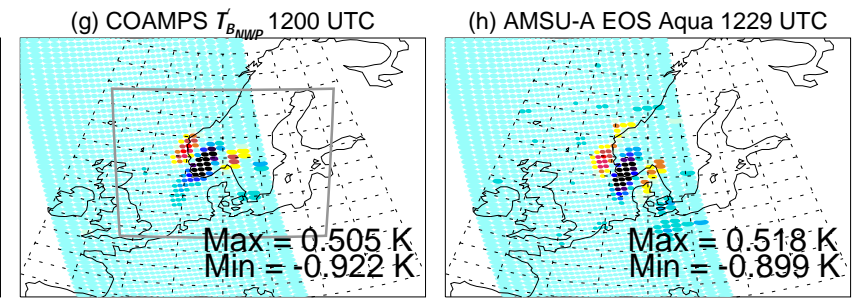

Fig. 15. Same presentation as Fig. 14, but now plotting NWP brightness temperature perturbations derived by extracting them from mean values via Eq. (6).

Figure 16 plots $T_{B_{\mathrm{NWP}}}^{\prime}\left(\hat{\lambda}_{j}, \hat{\phi}_{j}\right)$ maps based on NOGAPSALPHA temperature fields at times closest to the corresponding measurements from all 8 AMSU-A overpasses in Fig. 6. Many aspects of the measurements in Fig. 6 are reproduced in Fig. 16. For example, at 01:00-02:00 UTC the perturbation maps look very similar despite showing no obvious wave perturbations over southern Scandinavia and small amplitudes near nominal AMSU-A noise floors of $\sim 0.15-0.2 \mathrm{~K}$. At $~ 07: 00$ UTC the wave appears weakly overly southern Scandinavia, then grows in amplitude during the period 07:00-12:00 UTC. The horizontal wavelength, geographical extent, orientation and phase all agree well with observed fluctuations in Fig. 6. At 17:00 UTC and 20:00 UTC the wave phase fronts are rotated clockwise compared to earlier times, the packet width is broader, the wavelength is longer, and the oscillation is dominated by a large-amplitude cold phase that extends farther northward and southward: all these features are seen in the observed maps in Figs. 6g and $h$. The main differences are in the amplitudes. For the first 6 panels, the NOGAPS-ALPHA brightness temperature amplitudes in Fig. 16 are smaller than those observed in Fig. 6. Whereas the largest observed perturbation amplitudes occur at $\sim 12: 00$ UTC in Fig. 6, the largest NOGAPSALPHA brightness temperature amplitudes in Fig. 16 occur at 17:00 UTC and 20:00 UTC. This is due (at least in part) to the longer horizontal wavelength at these later times (see, e.g., Fig. 7b), which NOGAPS-ALPHA can explicitly simulate at T239L60 with less amplitude attenuation (Skamarock, 2004).

Since the T239L60 NOGAPS-ALPHA runs underestimate this wave's amplitude, we repeated these calculations using the hourly COAMPS fields. However, the regional COAMPS domain complicates these calculations. Specifically, when the numerical extraction methods used for AMSU-A data are applied to model brightness temperatures within this re- gional COAMPS domain only, they produce edge effects at the lateral boundaries which severely contaminate the estimated perturbation fields. To circumvent this issue, we generated artificial temperature fields at measurement locations outside the COAMPS domain by averaging COAMPS temperatures that were within $200 \mathrm{~km}$ of the measurement point under consideration. If less than 50 COAMPS gridpoints values were within $200 \mathrm{~km}$ of the measurement point, we averaged the 50 nearest gridpoint temperatures. We did this at each model level, then converted this artifical temperature profile into a brightness temperature by integrating vertically using the vertical AMSU-A weighting function $W_{j}(Z)$. Once a full map of brightness temperature data was generated (both model-based fields inside and artificial fields outside the COAMPS domain), we proceeded as before, computing means and then isolating fluctuations using Eq. (6).

Figure 17 plots these COAMPS-based $T_{B_{\mathrm{NWP}}}^{\prime}\left(\hat{\lambda}_{j}, \hat{\phi}_{j}\right)$ maps. The main differences from the NOGAPS-ALPHA fields in Fig. 16 are the larger amplitudes, as expected. These COAMPS fields agree quite well with AMSU-A data from the corresponding panels of Fig. 6. Overall, the largest COAMPS brightness temperature amplitudes are slightly larger than those observed in Fig. 6. Like the observations, the COAMPS fields return largest brightness temperature amplitudes at 12:00 UTC, with slightly smaller values at later times.

To provide more quantitative comparisons, Fig. 18 plots observed and model-generated brightness temperature perturbations for the final four AMSU-A measurements, computed along the longitude-latitude trajectory previously used in Figs. 7 and 8 and replotted for reference in panels (e-h) of Fig. 17. Generally there is impressive agreement in amplitude and phase between the observed and model-generated brightness temperature fluctuations in all four panels, with only slight phase differences between observed and model 

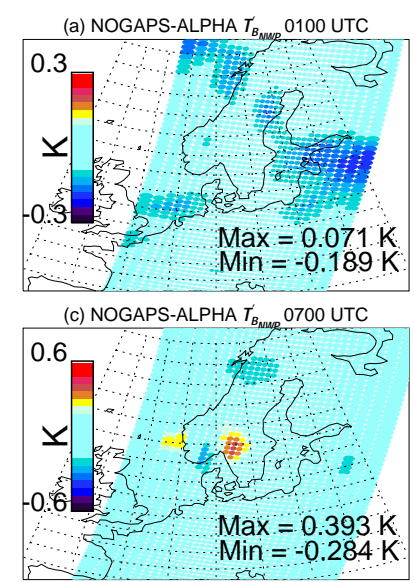

(e) NOGAPS-ALPHA $T_{B_{\text {Nup }}} 1200$ UTC

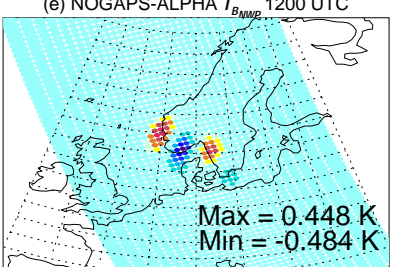

(g) NOGAPS-ALPHA $T_{B_{\text {NWP }}}, 1700$ UTC
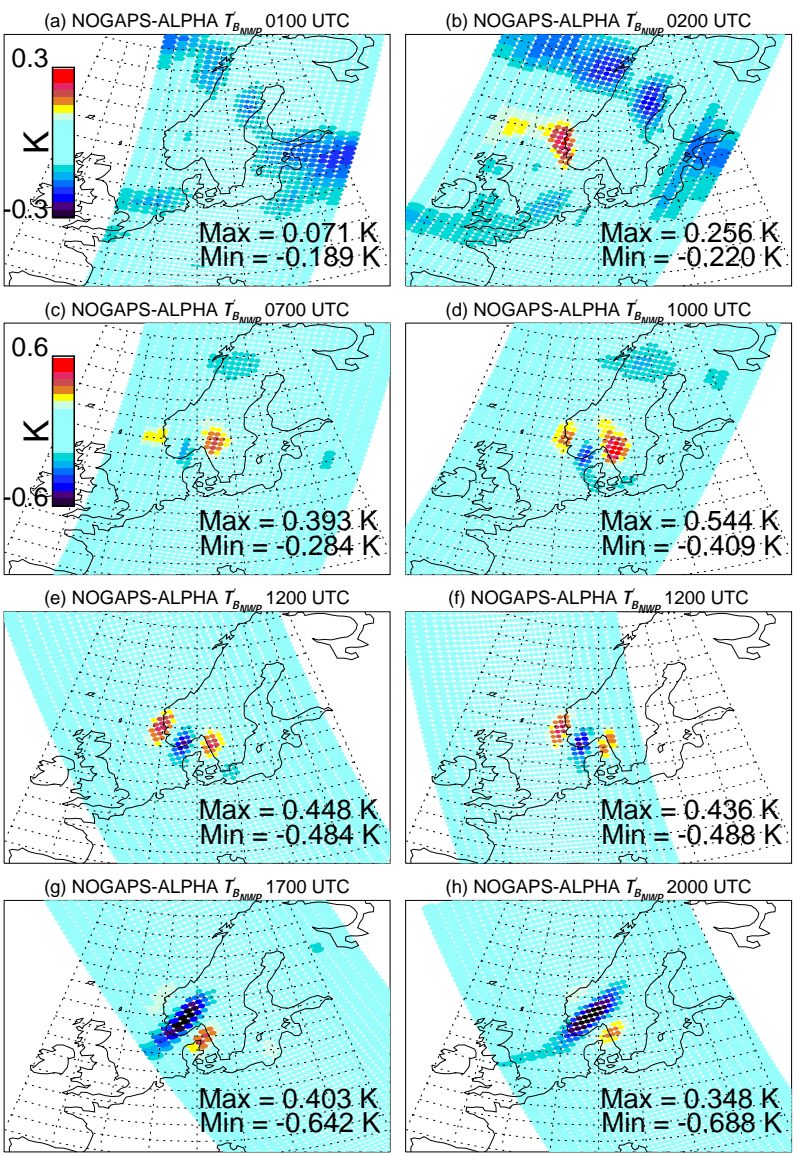

(d) NOGAPS-ALPHA $T_{B_{\text {NWP }}} 1000$ UTC

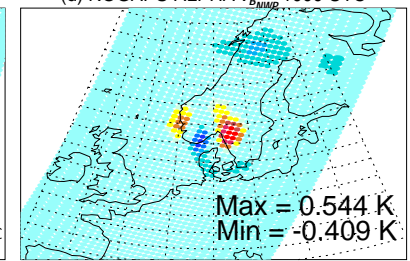

(f) NOGAPS-ALPHA $T_{B_{N w P}}^{\prime} 1200$ UTC

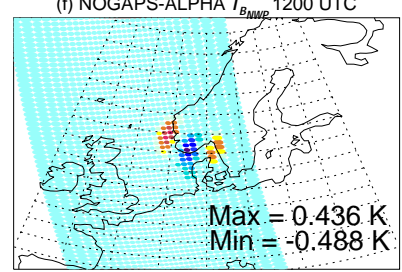

(h) NOGAPS-ALPHA $T_{B_{\text {NWP }}} 2000$ UTC

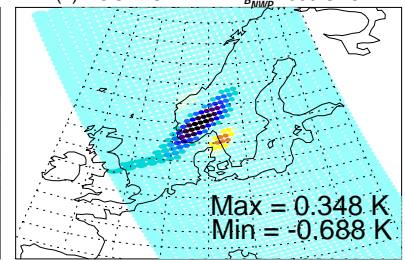

Fig. 16. Similar presentation to Fig. 6, but showing brightness temperature perturbations $T_{B \text { NWP }}^{\prime}\left(\hat{\lambda}_{j}, \hat{\phi}_{j}\right)$ derived via Eqs. (2) and (6) from the hourly NOGAPS-ALPHA temperature hindcast field closest in time to the satellite overpass in question. Values are in Kelvin (see color bars): for panels (a) and (b) the range is $\pm 0.3 \mathrm{~K}$, whereas for panels (c-h) the color bar range is $\pm 0.6 \mathrm{~K}$. Maximum and minimum values for each map are shown in the lower-right portion of each panel.

fields evident for the final 20:23 UTC NOAA-17 overpass. The close agreement between these model-generated and observed brightness temperature oscillations in Fig. 18 provides an absolute validation of the gravity wave detection and imaging capabilities of AMSU-A Channel 9 radiances suggested by the modeling study of Eckermann and Wu (2006).

\section{Summary and conclusions}

This study has focused on structure in lower stratospheric radiances acquired from AMSU-A Channel 9 during 8 satellite overpasses of southern Scandinavia on 14 January 2003. On removing large-scale horizontal structure from the raw "pushbroom" radiance imagery, plane wave-like oscillatory structures were revealed over southern Scandinavia with horizontal wavelengths of $\sim 400-500 \mathrm{~km}$ and amplitudes of
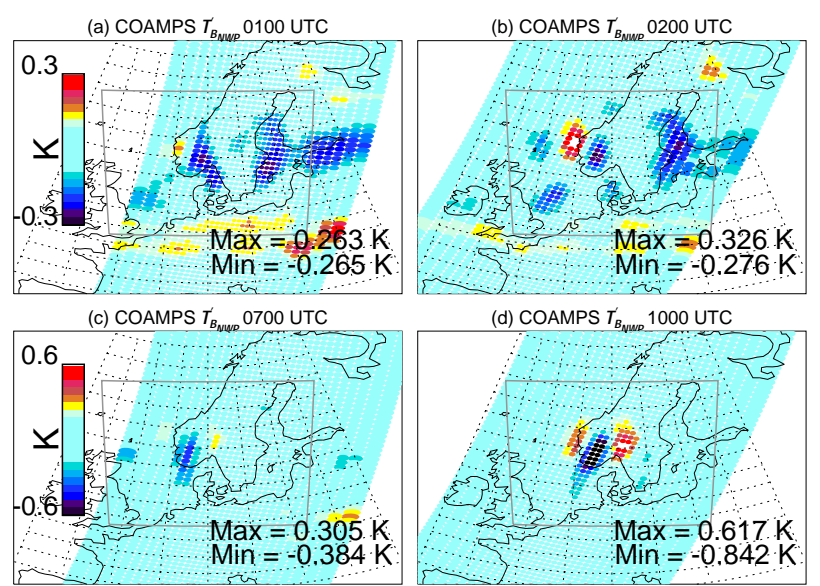

(e) COAMPS $T_{B_{\text {NWP }}} 1200$ UTC
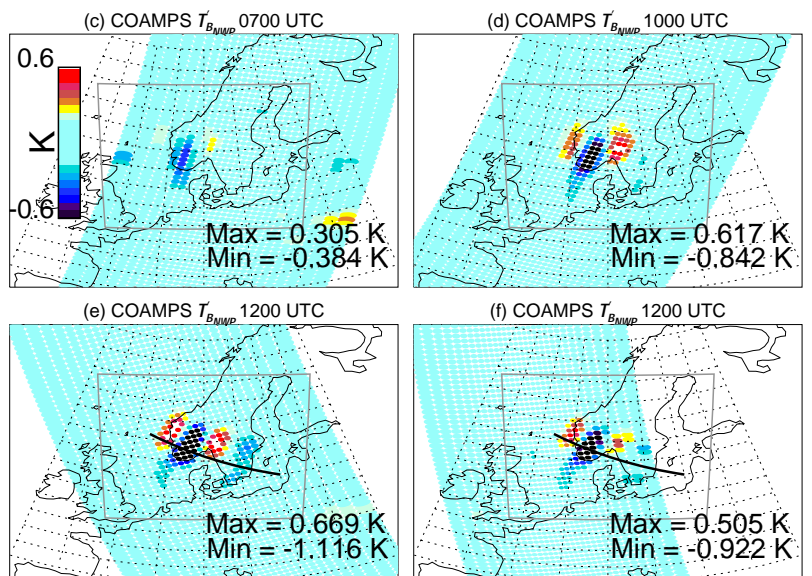

(g) COAMPS $T_{B_{\text {NWP }}} 1700$ UTC
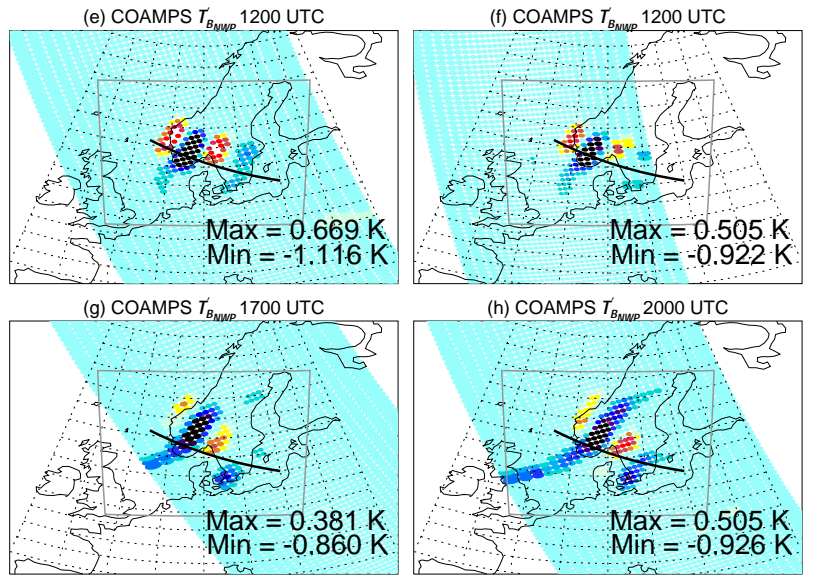

(h) COAMPS $T_{B_{N W P}} 2000$ UTC

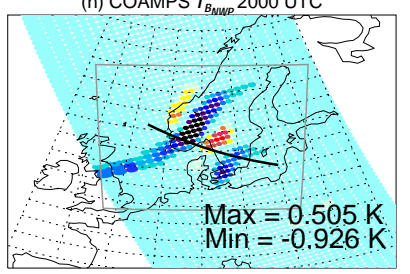

Fig. 17. Same presentation as Fig. 16, but showing brightness temperature perturbations $T_{B_{\mathrm{NWP}}}^{\prime}\left(\hat{\lambda}_{j}, \hat{\phi}_{j}\right)$ derived from hourly COAMPS temperature fields. Gray curve shows borders of the COAMPS domain. Black curves in panels $(\mathbf{e}-\mathbf{h})$ reproduce the cross section from Figs. 7a and 8 along which brightness temperatures are profiled in Fig. 18.

up to $\sim 0.9 \mathrm{~K}$. Modeling studies by Eckermann and $\mathrm{Wu}$ (2006) indicated that long-wavelength large-amplitude gravity waves within the measurement volumes scanned by AMSU-A can produce this type of radiance structure. In such cases, this structure represents a quasi-horizontal measurement cross section through the 3-D gravity-wave oscillations near the 60-90 hPa peak in the Channel 9 weighting function. If validated, such measurements would provide an important new horizontal imaging capability for stratospheric gravity waves.

To test this hypothesis, we first accessed 3-D temperature fields for 14 January 2003 from forecast and hindcast runs from a suite of high-resolution NWP models. We simulated Channel 9 radiance acquisition from these temperature fields using actual AMSU-A scanning patterns from each satellite overpass. In each case, the radiance map that resulted was very similar in overall structure to the raw imagery. This provided preliminary validation of the 3-D AMSU-A 

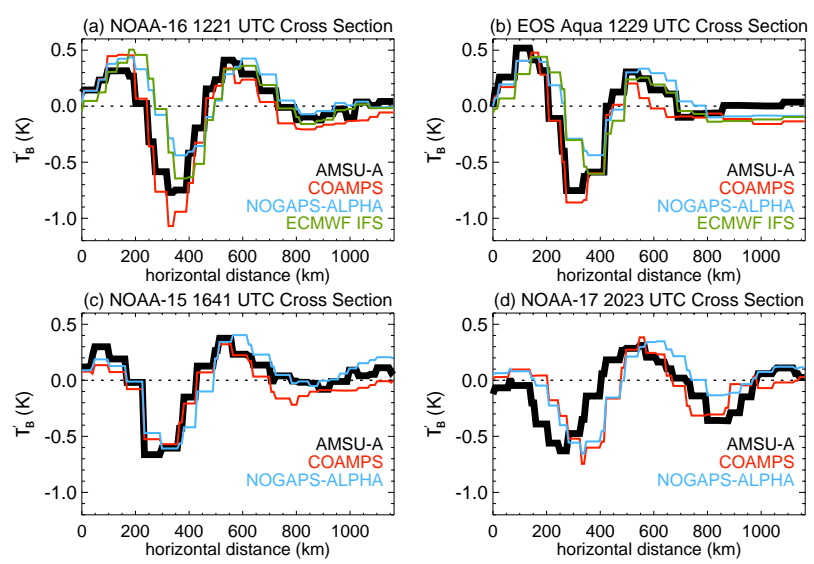

Fig. 18. Black curves show AMSU-A brightness temperature perturbations as a function of horizontal distance from left to right along the horizontal trajectory plotted in black in Figs. 7a and 17e$\mathrm{h}$, for overpasses of (a) NOAA-16 at 12:21 UTC, (b) EOS Aqua at 12:29 UTC, (c) NOAA-15 at 16:41 UTC, and (d) NOAA-17 at 20:23 UTC. Green curves in (a) and (b) show synthetic brightness temperature perturbations based on 12:00 UTC $(+24 \mathrm{~h}$ forecast) ECMWF IFS temperatures. ECMWF IFS curves are omitted from panels (c) and (d) since the 18:00 UTC fields closest in time to these measurements were not available from the archives. Blue and red curves show synthetic brightness temperature perturbations derived from hourly NOGAPS-ALPHA and COAMPS fields plotted in Figs. 16 and 17, respectively.

Channel 9 temperature weighting functions of Eckermann and $\mathrm{Wu}$ (2006) that were used to perform these forwardmodel conversions.

Next we removed large-scale horizontal structure from the NWP temperature fields to isolate small-scale perturbations. Large-amplitude gravity waves over southern Scandinavia were revealed in all three NWP model runs. These waves were generated by surface flow across the southern Scandinavian Mountains and propagated into the stratosphere. At $90 \mathrm{hPa}$, they had peak temperature amplitudes of $\sim 5$ $7 \mathrm{~K}$, horizontal wavelengths of $\sim 400-500 \mathrm{~km}$ and vertical wavelengths of $\sim 12 \mathrm{~km}$. Horizontal cross sections at $90 \mathrm{hPa}$ showed 2-D oscillatory temperature structures that were very similar to those seen in the AMSU-A radiances.

To validate these NWP fields objectively, we first compared the models' horizontal winds and temperatures to those acquired from a 12:00 UTC radiosonde ascent. The resolved gravity wave in the NWP fields produced oscillations along the 3-D radiosonde ascent trajectory that agreed closely in both amplitude and phase with similar oscillations in the radiosonde data. Next we profiled NWP temperatures along a NASA DC-8 flight segment over southern Scandinavia and compared them with vertical profiles of aerosol backscatter coefficients and temperatures acquired by onboard lidars. Wave-induced minima in the NWP temperatures corresponded closely in time and altitude with polar stratospheric clouds and temperature minima seen in the lidar profiles. In particular, we showed definitively that this gravity wave produced the high-altitude ice PSC measured at 07:00 UTC on this flight.

Finally, using the 3-D Channel 9 weighting functions of Eckermann and Wu (2006) and AMSU-A scan patterns from each of the 8 overpasses, we derived radiances from these 3D NWP wave temperature oscillations using forward-model integrations. In the first experiment, we simply scanned the NWP temperature fluctuations to acquire a corresponding AMSU-A brightness temperature oscillation. In the second, more realistic experiment, we scanned the raw NWP temperature field to acquire radiances, then removed the background radiance to isolate fluctuations using the same algorithms used to process the observed radiances. In both cases, radiance oscillations were produced from the resolved gravity waves in the NWP temperature fields that showed similar horizontal wavelengths, phase alignments, amplitudes and time variations from 00:00-20:00 UTC to those observed in the AMSU-A data. One-dimensional cross sections through the 2-D wave structure revealed excellent amplitude and phase agreement between observed and simulated radiance oscillations.

These findings prove that AMSU-A can both resolve and image lower stratospheric gravity waves in its Channel 9 radiances. They also formally validate the forward model predictions of Eckermann and Wu (2006) regarding anticipated brightness temperature oscillations for a 3-D gravity wave of given wavelengths and temperature amplitude. Given the success for Channel 9, this same modeling and validation approach could be extended to the other 5 AMSU-A stratospheric temperature channels, which would then provide validated horizontal imagery on long-wavelength gravity wave structures through the entire stratosphere (see, e.g., Wu and Zhang, 2004).

This AMSU-A horizontal imaging capability can provide much-needed global information on gravity wave horizontal wavelengths and horizontal propagation directions in the stratosphere, which are critical inputs to stratospheric gravity wave drag (GWD) parameterizations in NWP and climate models (Kim et al., 2003). Since suborbital vertical profiling instruments and orbital limb sensors can measure the vertical wavelengths of stratospheric gravity waves they resolve, then combining such a measurement with contemporaneous horizontal imagery from AMSU-A can fully characterize the three-dimensional structure of the gravity wave, providing it has wavelengths long enough to be visible to both instruments. This 3-D wavelength characterization would in turn permit accurate estimates of important additional constraint parameters for GWD parameterizations, such as vertical fluxes of horizontal pseudomomentum densities (see, e.g., Eckermann and Preusse, 1999; Ern et al., 2004).

Acknowledgements. COAMPS ${ }^{\circledR}$ is a registered trademark of the Naval Research Laboratory. This work was partially sponsored 
by NASA's Earth Science and Geospace Sciences Programs, and by the Office of Naval Research. The NOGAPS-ALPHA runs were supported in part by a grant of computer time from the DoD High Performance Computing Modernization Program at the U.S. Army Engineer Research and Development Center, Vicksburg, Mississippi.

Edited by: W. Ward

\section{References}

Allen, D. R., Coy, L., Eckermann, S. D., McCormack, J. P., Manney, G. L., Hogan, T. F., and Kim, Y.-J.: NOGAPS-ALPHA simulations of the 2002 Southern Hemisphere stratospheric major warming, Mon. Wea. Rev., 134, 498-518, 2006.

Alexander, M. J.: Interpretations of observed climatological patterns in stratospheric gravity wave variance, J. Geophys. Res., 103, 8627-8640, 1998.

Baker, N. L., Hogan, T. F., Campbell, W. F., Pauley, R. L., and Swadley, S. D.: The impact of AMSU-A radiance assimilation in the U.S. Navy's Operational Global Atmospheric Prediction System (NOGAPS), Naval Research Laboratory Memorandum Report, NRL/MR/7530-05-8836, 22pp, 4 February, 2005.

Barker, E.: Design of the Navy's multivariate optimum interpolation analysis system, Wea. Forecasting, 7, 220-231, 1992.

Burris, J., McGee, T., Hoegy, W., Lait, L., Twigg, L., Sumnicht, G., Heaps, W., Hostetler, C., Bui, T. P., Neuber, R., and McDermid, S.: Validation of temperature measurements from the airborne Raman ozone temperature and aerosol lidar during SOLVE, J. Geophys. Res., 107(D20), 8286, doi:10.1029/2001JD001028, 2002a.

Burris, J., McGee, T., Hoegy, W., Newman, P., Lait, L., Twigg, L., Sumnicht, G., Heaps, W., Hostetler, C., Neuber, R., and Künzi, K. F.: Lidar temperature measurements during the SOLVE campaign and the absence of polar stratospheric clouds from regions of very cold air, J. Geophys. Res., 107(D20), 8297, doi:10.1029/2001JD001036, 2002b.

Butchart, N. and Austin, J.: Middle atmosphere climatologies from the troposphere-stratosphere configuration of the UKMO's unified model, J. Atmos. Sci., 55, 2782-2809, 1998.

Daley, R. and Barker, E.: NAVDAS: formulation and diagnostics, Mon. Wea. Rev., 129, 869-883, 2001.

Davies, L. A. and Brown, A. R.: Assessment of which scales of orography can be credibly resolved in a numerical model, Q. J. R. Meteorol. Soc., 127, 1225-1237, 2001.

Derber, J., Pan, H.-L., Alpert, J., Caplan, P., White, G., Iredell, M., Hou, Y.-T., Campana, K., and Moorthi, S.: Changes to the 1998 NCEP operational MRF model analysis/forecast system, National Weather Service Technical Procedures Bulletin, 449, 37pp, 1998, available online at http://www.nws.noaa.gov/ om/tpb/indexb.htm.

Dewan, E. M., Picard, R. H., O’Neil, R. R., Gardiner, H. A., Gibson, J., Mill, J. D., Richards, E., Kendra, M., and Gallery, W. O.: MSX satellite observations of thunderstorm-generated gravity waves in mid-wave infrared images of the upper stratosphere, Geophys. Res. Lett., 25, 939-942, 1998.

Dörnbrack, A., Leutbecher, M., Kivi, R., and Kyrö, E.: Mountain wave-induced record low stratospheric temperatures above northern Scandinavia, Tellus, 51A, 951-963, 1999.

Dörnbrack, A., Birner, T., Fix, A., Flentje, H., Meister, A., Schmid, H., Browell, E. V., and Mahoney, M. J.: Evidence for inertia gravity waves forming polar stratospheric clouds over Scandinavia, J. Geophys. Res., 107(D20), 8287, doi:10.1029/2001JD000452, 2002.

Eckermann, S. D. and Preusse, P.: Global measurements of stratospheric mountain waves from space, Science, 286, 1534-1537, 1999.

Eckermann, S. D. and Wu, D. L.: Imaging gravity waves in lower stratospheric AMSU-A radiances, Part 1: Simple forward model, Atmos. Chem. Phys., 6, 3325-3341, 2006, http://www.atmos-chem-phys.net/6/3325/2006/.

Eckermann, S. D., McCormack, J. P., Coy, L., Allen, D., Hogan, T., and Kim, Y.-J.: NOGAPS-ALPHA: A prototype highaltitude global NWP model, Preprint Vol. Symposium on the 50th. Anniversary of Operational Numerical Weather Prediction, American Meteorological Society, University of Maryland, College Park, MD, 14-17 June, Paper P2.6, 23pp, 2004, available online at http://uap-www.nrl.navy.mil/dynamics/ papers/Eckermann_P2.6-reprint.pdf.

Eckermann, S. D., Dörnbrack, A., Vosper, S. B., Hostetler, C. A., Flentje, H., Mahoney, M. J., Bui, T. P., and Carslaw, K. S.: Mountain wave-induced polar stratospheric cloud forecasts for aircraft science flights during SOLVE/THESEO 2000, Wea. Forecasting, 21, 42-68, 2006.

Ern, M., Preusse, P., Alexander, M. J., and Warner, C. D.: Absolute values of gravity wave momentum flux derived from satellite data, J. Geophys. Res., 109, D20103, doi:10.1029/2004JD004752, 2004.

Errico, R. M., Barker, E. H., and Gelaro, R.: A determination of balanced normal modes for two models, Mon. Wea. Rev., 116, 2717-2724, 1988.

Feng, W., Chipperfield, M. P., Davies, S., Sen, B., Toon, G., Blavier, J. F., Webster, C. R., Volk, C. M., Ulanovsky, A., Ravegnani, F., von der Gathen, P., Jost, H., Richard, E. C., and Claude, H.: Three-dimensional model study of the Arctic ozone loss in 2002/2003 and comparison with 1999/2000 and 2003/2004, Atmos. Chem. Phys., 5, 139-152, 2005, http://www.atmos-chem-phys.net/5/139/2005/.

Fleming, E. L., Chandra, S., Barnett, J. J., and Corney, M.: Zonal mean temperature, pressure, zonal wind, and geopotential height as functions of latitude, COSPAR International Reference Atmosphere: 1986, Part II: Middle Atmosphere Models, Adv. Space Res., 10(12), 11-59, 1990.

Fueglistaler, S., Buss, S., Luo, B. P., Wernli, H., Flentje, H., Hostetler, C. A., Poole, L. R., Carslaw, K. S., and Peter, T.: Detailed modeling of mountain wave PSCs, Atmos. Chem. Phys., 3, 697-712, 2003, http://www.atmos-chem-phys.net/3/697/2003/.

Gal-Chen, T. and Somerville, R.: On the use of a coordinate transformation for the solution of the Navier-Stokes equations, J. Computational Phys., 17, 209-228, 1975.

Goerrs, J. S. and Phoebus, P. A.: The Navy's operational atmospheric analysis, Wea. Forecasting, 7, 232-249, 1992.

Goldberg, M. D., Crosby, D. S., and Zhou, L.: The limb adjustment of AMSU-A observations: methodology and validation, J. Appl. Meteor., 40, 70-83, 2001.

Hamilton, K., Wilson, R. J., and Hemler, R. S.: Middle atmosphere 
simulated with high vertical and horizontal resolution versions of a GCM: improvements in the cold pole bias and generation of a QBO-like oscillation in the tropics, J. Atmos. Sci., 56, 38293846, 1999.

Hanson, D. and Mauersberger, K.: Laboratory studies of the nitric acid trihydrate: implications for the South Pole stratosphere, Geophys. Res. Lett., 15, 855-858, 1988.

Hertzog, A., Vial, F., Dörnbrack, A., Eckermann, S. D., Knudsen, B. M., and Pommereau, J.-P.: In-situ observations of gravity waves and comparisons with numerical simulations during the SOLVE/THESEO 2000 campaign, J. Geophys. Res., 107(D20), 8292, doi:10.1029/2001JD001025, 2002.

Hodur, R. M.: The Naval Research Laboratory's Coupled Ocean/Atmosphere Mesoscale Prediction System (COAMPS), Mon. Wea. Rev., 125, 1414-1430, 1997.

Hogan, T. F. and Rosmond, T.: The description of the Navy Operational Global Atmospheric Prediction System's spectral forecast model, Mon. Wea. Rev., 119, 1786-1815, 1991.

Jiang, J. H., Wu, D. L., and Eckermann, S. D.: Upper Atmosphere Research Satellite (UARS) MLS observation of mountain waves over the Andes, J. Geophys. Res., 107(D20), doi:10.1029/2002JD002091, 2002.

Jiang, J. H., Eckermann, S. D., Wu, D. L., and Ma, J.: A search for mountain waves in MLS stratospheric limb radiances from the Northern Hemisphere: data analysis and global mountain wave modeling, J. Geophys. Res., 109, D03107, doi:10.1029/2003JD003974, 2004.

Kidder, S. Q., Goldberg, M. D., Zehr, R. M., DeMaria, M., Purdom, J. F. W., Velden, C. S., Grody, N. C., and Kusselson, S. J.: Satellite analysis of tropical cyclones using the Advanced Microwave Sounding Unit (AMSU), Bull. Amer. Meteorol. Soc., 81, 12411259, 2000.

Kim, Y.-J., Eckermann, S. D., and Chun, H.-Y.: A overview of the past, present and future of gravity-wave drag parameterization for numerical climate and weather prediction models, Atmos. Ocean, 41, 65-98, 2003.

Kivi, R., Kyrö, E., Dörnbrack, A., and Birner, T.: Observations of vertically thick polar stratospheric clouds and record low temperature in the Arctic vortex, Geophys. Res. Lett., 28, 3661-3664, 2001.

Lambrigtsen, B. H.: Calibration of the AIRS microwave instruments, IEEE Trans. Geosci. Remote Sens., 41, 369-378, 2003.

Lander, J. and Hoskins, B. J.: Believable scales and parameterizations in a spectral transform model, Mon. Wea. Rev., 125, 292303, 1997.

Lane, T. P., Reeder, M. J., Morton, B. R., and Clark, T. L.: Observations and numerical modeling of mountain waves over the Southern Alps of New Zealand, Quart. J. Roy. Meteorol. Soc., 126, 2765-2788, 2000.

Marti, J. and Mauersberger, K.: A survey and new measurements of ice vapor-pressure at temperatures between 170 and $250 \mathrm{~K}$, Geophys. Res. Lett., 20, 363-366, 1993.

McCormack, J. P., Eckermann, S. D., Coy, L. Allen, D. R., Kim, Y.J., Hogan, T., Lawrence, B. N., Stephens, A., Browell, E. V., Burris, J., McGee, T., and Trepte, C. R.: NOGAPS-ALPHA model simulations of stratospheric ozone during the SOLVE2 campaign, Atmos. Chem. Phys., 4, 2401-2423, 2004, http://www.atmos-chem-phys.net/4/2401/2004/.
McLandress, C., Alexander, M. J., and Wu, D. L.: Microwave limb sounder observations of gravity waves in the stratosphere: a climatology and interpretation, J. Geophys. Res., 105, 1947-1967, 2000.

Mo, T.: Prelaunch calibration of the Advanced Microwave Sounding Unit-A for NOAA-K, IEEE Trans. Microwave Theory Tech., 44, 1460-1469, 1996.

O'Sullivan, D. and Dunkerton, T. J.: Generation of inertia gravity waves in a simulated life cycle of baroclinic instability, J. Atmos. Sci., 52, 3695-3716, 1995.

Preusse, P., Dörnbrack, A., Eckermann, S. D., Riese, M., Schaeler, B., Bacmeister, J. T., Broutman, D., and Grossmann, K. U.: Space-based measurements of stratospheric mountain waves by CRISTA, 1, Sensitivity, analysis method, and a case study, J. Geophys. Res., 107(D23), 8178, doi:10.1029/2001JD000699, 2002.

Reale, A. L., Chalfant, M. W., Allegrino, A. S., Tilley, F. H., Ferguson, M. P., and Pettey, M. E.: Advanced TOVS (ATOVS) sounding products from NOAA polar orbiting environmental satellites, Paper JP1.15, 12th. Conference on Satellite Meteorology and Oceanography, American Meteorological Society, Seattle, WA, 16pp, 11-15 January, 2004, available online at http://ams.confex.com/ams/pdfpapers/56756.pdf.

Ritchie, H., Temperton, C., Simmons, A. J., Hortal, M., Davies, T., Dent, D., and Hamrud, M.: Implementation of the semiLagrangian method in a high-resolution version of the ECMWF forecast model, Mon. Wea. Rev., 123, 489-514, 1995.

Shutts, G. J., Kitchen, M., and Hoare, P. H.: A large amplitude gravity wave in the lower stratosphere detected by radiosonde, Quart. J. Roy. Meteor. Soc., 114, 579-594, 1988.

Skamarock, W. C.: Evaluating mesoscale NWP models using kinetic energy spectra, Mon. Wea. Rev., 132, 3019-3032, 2004.

Swinbank, R. and Ortland, D. A.: Compilation of wind data for the Upper Atmosphere Research Satellite (UARS) reference atmosphere project, J. Geophys. Res., 108(D19), 4615, doi:10.1029/2002JD003135, 2003.

Untch, A. and Hortal, M.: A finite-element scheme for the vertical discretization of the semi-Lagrangian version of the ECMWF forecast model, Quart. J. Roy. Meteor. Soc., 130, 1505-1530, 2004.

Webster, S., Brown, A. R., Cameron, D. R., and Jones, C. P.: Improvements to the representation of orography in the Met Office Unified Model, Quart. J. Roy. Meteor. Soc., 129, 1989-2010, 2003.

Wu, D. L.: Mesoscale gravity wave variances from AMSU-A radiances, Geophys. Res. Lett., 31, L112114, doi:10.1029/2004GL019562, 2004.

Wu, D. L. and Zhang, F.: A study of mesoscale gravity waves over the North Atlantic with satellite observations and a mesoscale model, J. Geophys. Res., 109, D22104, doi:10.1029/2004JD005090, 2004.

Wu, D. L., Preusse, P., Eckermann, S. D., Jiang, J. H., de la Torre Juarez, M., Coy, L., and Wang, D. Y.: Remote sounding of atmospheric gravity waves with satellite limb and nadir techniques, Adv. Space Res., 37, 2269-2277, 2006. 